NBER WORKING PAPER SERIES

\title{
DEBT AND CREATIVE DESTRUCTION: WHY COULD SUBSIDIZING CORPORATE DEBT BE OPTIMAL?
}

\author{
Zhiguo He \\ Gregor Matvos \\ Working Paper 17920 \\ http://www.nber.org/papers/w17920
NATIONAL BUREAU OF ECONOMIC RESEARCH
1050 Massachusetts Avenue
Cambridge, MA 02138
March 2012

We thank Raj Chetty, Douglas Diamond, Peter DeMarzo, Raghu Rajan, Amit Seru, Rob Vishny and the participants of the Chicago Booth Finance Lunch and Chicago Booth Applied Theory seminar for helpful comments. The views expressed herein are those of the authors and do not necessarily reflect the views of the National Bureau of Economic Research.

NBER working papers are circulated for discussion and comment purposes. They have not been peerreviewed or been subject to the review by the NBER Board of Directors that accompanies official NBER publications.

(C) 2012 by Zhiguo He and Gregor Matvos. All rights reserved. Short sections of text, not to exceed two paragraphs, may be quoted without explicit permission provided that full credit, including $\odot$ notice, is given to the source. 
Debt and Creative Destruction: Why Could Subsidizing Corporate Debt be Optimal?

Zhiguo He and Gregor Matvos

NBER Working Paper No. 17920

March 2012

JEL No. D82,G32,H25

\begin{abstract}
$\underline{\text { ABSTRACT }}$
We illustrate the welfare benefit of tax subsidies to corporate debt financing. Two firms engage in a socially wasteful competition for survival in a declining industry. Firms differ on two dimensions: exogenous productivity and endogenously chosen amount of debt financing, resulting in a two dimensional war of attrition. Debt financing increases incentives to exit, which, while socially beneficial, is costly for the firm. Therefore the planner can increase welfare by subsidizing debt financing. The duration of industry distress determines the tradeoff between the welfare benefit illustrated in our model and the costs of subsidizing corporate debt from the existing literature. Our theory also sheds light on why the IRS considers "conflict of interest" as one of the key determinants in identifying securities that are qualified for tax-benefits.
\end{abstract}

\author{
Zhiguo He \\ University of Chicago \\ Booth School of Business \\ Zhiguo.He@ChicagoBooth.edu
}

Gregor Matvos

Booth School of Business

University of Chicago

5807 South Woodlawn Avenue

Chicago, IL 60637

and NBER

gmatvos@chicagobooth.edu 


\title{
Debt and Creative Destruction: Why Could Subsidizing Corporate Debt be Optimal?*
}

\author{
Zhiguo $\mathrm{He}^{\dagger} \quad$ Gregor Matvos ${ }^{\ddagger}$
}

First Draft: August 2011

This Draft: March 2012

\begin{abstract}
We illustrate the welfare benefit of tax subsidies to corporate debt financing. Two firms engage in a socially wasteful competition for survival in a declining industry. Firms differ on two dimensions: exogenous productivity and endogenously chosen amount of debt financing, resulting in a two dimensional war of attrition. Debt financing increases incentives to exit, which, while socially beneficial, is costly for the firm. Therefore the planner can increase welfare by subsidizing debt financing. The duration of industry distress determines the tradeoff between the welfare benefit illustrated in our model and the costs of subsidizing corporate debt from the existing literature. Our theory also sheds light on why the IRS considers "conflict of interest" as one of the key determinants in identifying securities that are qualified for tax-benefits.
\end{abstract}

Key Words: War of Attrition with Asymmetric Information, Externality, Endogenous Types, Debt Tax Shield, Capital Structure, Tax Policy.

JEL Code. H25, G32, D82

\section{Introduction}

Corporations can deduct interest payments from their profits, giving rise to the so-called debt tax shield. This subsidy to debt financing is massive, comprising 9.7 percent of firm value in the United States (Graham, 2000) and provides firms with incentives to obtain financing through debt relative to equity. While very little research explicitly considers the welfare consequences of

\footnotetext{
${ }^{*}$ We thank Raj Chetty, Douglas Diamond, Peter DeMarzo, Raghu Rajan, Amit Seru, Rob Vishny and the participants of the Chicago Booth Finance Lunch and Chicago Booth Applied Theory seminar for helpful comments.

${ }^{\dagger}$ University of Chicago, Booth School of Business, zhiguo.he@ chicagobooth.edu.

${ }^{\ddagger}$ University of Chicago, Booth School of Business and NBER, gregor.matvos@ chicagobooth.edu.
} 
this subsidy, most theories suggest that if debt financing has externalities, they are negative (e.g., Lorenzoni, 2008). Indeed, this belief has been the driving force behind policy proposals over the last two decades to eliminate the debt subsidy. For example, President Bush's Advisory Panel on Federal Tax Reform recommended that the tax system should "provide a more level treatment of debt and equity financing for large businesses" and justified it the following way: ${ }^{1}$

"The tax bias against corporate equity encourages firms to rely on debt more than they would if the tax system imposed no such bias. The use of higher debt levels known as "leveraging" may increase the risk of bankruptcy and financial distress during temporary industry or economy-wide downturns. This heightened bankruptcy risk can make the entire economy more volatile."

The backbone of these models is that temporary shocks cause bankruptcy of efficient firms. However, as early as Schumpter (1934) economists have recognized that liquidating inefficient firms can also be important. Such liquidation redeploys assets to alternative firms and sectors, and stops inefficient further investment. This reallocation can be especially important when economies are transitioning from permanent demand and technological innovation shocks, which render some industries obsolete and at overcapacity.

Often in declining industries weak firms do not exit as fast as is socially optimal if they engage in a war of attrition (e.g., Fudenberg and Tirole, 1986). In fact, firms not only compete to survive, but may also continue to invest, as eloquently described by Jensen (1993): "In industry after industry with excess capacity, managers fail to recognize that they themselves must downsize; instead they leave the exit to others while they continue to invest. When all managers behave this way, exit is significantly delayed at substantial cost of real resources to society."

Our model explores the effect that subsidizing debt financing has on firms' exit in declining industries. We embed the classic conflict of interest between equity and debt (Jensen and Meckling, 1976; Leland, 1994) into a war of attrition model. In this conflict, equity holders ex post fail to internalize the bankruptcy costs that accrue to debt holders and therefore file for bankruptcy earlier than would be optimal from the perspective of the firm as a whole. Similar to standard models, this conflict lowers firm value. In our model, however, the conflict also alleviates the socially wasteful war of attrition. Therefore, in sharp contrast to much of the previous literature, we emphasize that the conflict of interest between debt and equity can be socially desirable and illustrate a benefit of subsidizing debt. We further show that the tradeoff between the cost and benefit of subsidizing debt depends on whether the shocks to the industry are temporary or permanent.

Consider the recent developments in the brick-and-mortar book retail industry. Amazon's

\footnotetext{
${ }^{1}$ Report of the President's Advisory Panel on Federal Tax Reform, November 2005, p. 100. Several tax reform proposals during the Clinton administration had proposed the elimination of unequal treatment of debt and equity (Congressional Budget Office, 1997). Recently, the Chairmen of the Senate Finance and House Ways and Means Committee had requested a study of tax treatment of debt and equity (Wall Street Journals, 2011).
} 
entry had decreased demand for purchasing books in physical stores. As early as 2005 bookselling had become "a game of stealing market share from competitors" (Barron's, 2005) with two major players, Borders and Barnes and Noble. Nevertheless, neither Borders nor Barnes and Noble were reducing the number of stores they operated. For example, Borders was investing in stores for most of the 2000s (U.S. News, 2011). It was Borders' bankruptcy on February 16, 2011 that finally significantly reduced the number of stores. Barnes and Noble declined to purchase liquidated Borders stores, since 70 percent were within 5 miles of a their own stores. Instead, these stores are being converted to sell other products (The Times-Picayune, 2011). In fact, Barnes and Noble is expected to cut 10 percent of its stores in the near future (Business Week, 2011). This suggests that the industry was operating too many stores, which were used to fight for market share, instead of being allocated to socially efficient uses. The bankruptcy of Borders terminated a costly war of attrition and increased the value of the whole industry. Our model tries to capture the forces in this example and show the role of the government subsidy of debt. ${ }^{2}$

We start with two firms, which engage in an asymmetric information war of attrition as in Bulow and Klemperer (1999). The industry is at overcapacity and supports only one firm: the presence of a firm exerts a non pecuniary externality on the other firm. Before the war of attrition, each firm chooses its capital structure : equity holders raise debt in a competitive debt market. During the war of attrition equity holders can decide if they want to default by filing for bankruptcy, which leads to liquidation. The social planner can subsidize debt by subsidizing firms' debt repayment.

The distinguishing feature of our model is the two-dimensional type that determines firms' effective strength in the war of attrition. The first dimension is exogenously given productivity (i.e., real strength); and the second is endogenous amount of debt (i.e., financial strength). The equity holders' decision to raise more debt on the margin is based on the following tradeoff: The direct effect of increasing the promised debt payment, holding firm's exit strategy fixed, increases the price of debt and decreases the value of equity. Because the payment to debt is tax subsidized, this increases firm value. This is the main channel through which subsidizing debt affects debt levels in equilibrium. Marginally increasing debt also has an indirect effect on firm value through distorting exit times. Equity holders' benefits from winning decrease, therefore they choose to default sooner. This results in a lower price of debt, and, since exit times are distorted, it decreases the value of the firm. A firm's choice of debt equalizes these two effects on the margin.

\footnotetext{
${ }^{2}$ Personal electronics retail and video rentals are further examples of brick-and-mortar industries that had suffered a permanent demand shock, but only adjusted capacity after one of the major firms went bankrupt (Circuity City, Blockbuster). Internet retailing is not the only example of disruptive innovation that generated overcapacity in an industry. The innovation from ply to radial tires increased the life span of tires three to five times, dramatically reducing the tire demand and leaving the industry at overcapacity (Jensen 1993). For other examples of industries that required a significant contraction see Jensen (1993) whose examples range from the cereals, whisky and tin plate industries in the late nineteenth century to defense industries after the cold war.
} 
We solve for exit times and debt schedule in closed-form, which are jointly determined in equilibrium. We first prove that, in equilibrium, more productive firms are stronger in the war of attrition even after accounting for their debt choice. Therefore, in equilibrium, from a given firm's point of view, its opponents type becomes effectively one dimensional. This greatly improves the tractability of the model and allows us to solve for the unique symmetric equilibrium of this game. This result also has efficiency implications. One concern with subsidizing debt is that productive firms might "over leverage" to exploit the subsidies and ex-post sometimes exit sooner than less productive firms. Monotonicity in effective strength implies that there are no inefficiencies in sorting of firms' exits: if a firm is exiting, it must mean that any less productive firms would have exited already.

As a benchmark, we show that in economies with no debt subsidy, firms do not take on debt. Although the socially optimal allocation requires that the relatively weaker firm exits immediately, under all-equity financing, it will stay in the industry and engage in a socially wasteful war of attrition. A debt subsidy induces all firms to increase their debt levels in equilibrium. As each firm raises its debt level, its exit time shortens. This reduction in exit times is further reinforced in equilibrium. First, if any firm lowers its equilibrium exit time, all firms, which are more productive, respond by lowering exit times as well. Second, raising equilibrium debt levels of a given firm results in an equilibrium increase in debt for all more productive firms, reducing exit times further. Shorter exit times improve welfare by shortening wasteful wars of attrition and do not induce inefficient sorting of firms' exits. Therefore a planner can increase welfare through subsidizing debt.

Our model captures some of the richness in how the tax subsidy is implemented in the U.S. tax system (Section 4.1). The Internal Revenue Service (IRS) requires that debt holders and equity holders are distinct entities, and have conflicting liquidation preferences, if debt is to be subsidized. These IRS rules encourage conflict of interest, which is consistent with our model if the IRS acts as a social planner. Our theory naturally delivers several intriguing patterns in the implementation of debt tax subsidy in the U.S. tax system, raising the hurdle for alternative explanations of the debt tax subsidy, especially those in which the conflicts of interest is always welfare destroying.

In a way, that the debt subsidy increases welfare in our model is not surprising. Our model is designed to highlight the welfare benefits of debt, and not the costs, which have been well understood in the literature heretofore. In an extension we show that our welfare result critically hinges on the duration of industry distress. Relative to the benchmark model, the industry recovers in the future. The time to recovery plays a critical role: if the industry recovers quickly then debt may induce more exit than is socially optimal. This modification introduces the standard cost of subsidizing debt into the model, which the planner then has to trade-off with the benefits outlined above. As the duration of industry distress increases, the benefit of subsidizing debt rises and the 
cost falls. We show that while a positive subsidy to debt is optimal, raising it beyond a certain point can be welfare destroying.

In the second extension of the model we consider how asymmetric information in the financing stage affects the problem. Unlike in the benchmark model, in addition to firms, banks now cannot observe firm's productivity either and must infer it from debt choices. We show that including this additional friction does not alter the basic insights of the model. A positive debt subsidy still improves welfare by shortening a costly war of attrition.

We argue that subsidizing debt generates welfare benefits by reducing between firm externalities. Coase Theorem logic suggests that government intervention may not be necessary: a third party could purchase both firms in the industry and internalize the externality. Then wars of attrition would not arise in the first place. We examine this possibility and show that private information about productivity, which drives the war of attrition, also affects this "Coasian" solution. In fact, adverse selection facing a potential buyer is so extensive that she incurs a loss any time she attempts to internalize externalities. This is the case even if she faces no competition, and is allowed to offer time varying prices for the firms. Since the Coasian solution does not resolve the externality, there is room for the government to intervene with a debt subsidy. We do not use our model to argue that the debt subsidy is uniquely suited to reduce wars of attrition: one could conceive of more finely tuned policies that would target only industries at over-capacity. One unmodeled potential benefit of using the debt subsidy instead of such industrial policies is that its broad based nature is less subject to regulatory capture (Stigler, 1971).

Our theory, which gives one potential explanation for the use and implementation of debt tax subsidies in practice, takes a view that debt financing can result in positive externalities through creative destruction (Schumpter, 1934; and recently, Jovanovic and Tse, 2006). In contrast, most leading theories on incomplete financial markets focus on the negative externality of debt when firms suffer temporary shocks. ${ }^{3}$ Our approach is complementary to this literature. Instead of focusing on temporary shocks to productivity, we focus on permanent shocks, where the economy experiences permanent technological or demand shocks that leave some industries obsolete.

Debt financing has many potential benefits. For instance, that debt constrains potentially inefficient investment on the level of an individual firm has been recognized in the theoretical literature as early as Jensen and Meckling (1976). In such models with within-firm frictions, e.g., empire building, unverifiable investment, and asymmetric information, ${ }^{4}$ the second best allocation is achieved through capital structure choices that maximizes stakeholders' welfare. In other words,

\footnotetext{
${ }^{3}$ One particular mechanism wherein one firm's borrowing imposes negative externalities on others is the fire-sale channel (Shleifer and Vishny, 1992)_-given temporary shocks in productivity, efficient firms will be forced to cut back investment or even go bankrupt when the collateral value drops.

${ }^{4}$ For an extensive discussion for such models, see Harris and Raviv (1991) or Tirole (2006).
} 
private contracting internalizes these frictions and achieves the constrained optimal allocation, so the social planner cannot increase welfare through intervention. Our innovation is to highlight a between-firms externality so that the social planner can play a role.

Our modelling of capital structure is in the spirit of Leland (1994). In that model, optimal leverage balances the dead-weight bankruptcy cost due to the equity-debt conflict of interest with the benefit of the debt tax subsidy. Our model asks why the tax policy of subsidizing debt exists in the first place. In our model, bankruptcy is still costly from the perspective of an individual firm, but becomes socially beneficial. The equity-debt conflict of interest leads leveraged equity holders to exit sooner than they would otherwise, which alleviates the socially wasteful war of attrition. However, only a positive tax subsidy can entice the firm to borrow and impose the equity-debt conflict of interest on themselves.

War of attrition models date back to Maynard Smith (1974).$^{5}$ Our model, by allowing firms to choose capital structure before entering the war of attrition, introduces endogenous types in a setting similar to Bulow and Klemperer (1999). ${ }^{6}$ We show that, in equilibrium, more productive firms are effectively stronger in the war of attrition than less productive ones, and use this monotonicity property to solve the model. We use this game to study the welfare consequences of subsidizing corporate debt financing. ${ }^{7}$

Our paper is complementary to the current literature on welfare consequences of corporate taxation. While we focus on the welfare consequences of differential tax treatment of debt and equity financing, this literature has mainly explored welfare consequences of taxation of other corporate choices. Gordon and Dietz (2006) and Chetty and Saez (2010), for example, evaluate the welfare consequences of dividend tax changes. ${ }^{8}$ Their focus is on taxing firms' payouts to investors and the resulting distortions. Therefore they assume that the only outside financing in their model is equity. In our model payout policy does not play a role, since we allow equity holders to costlessly inject or remove cash from the firm. The literature on dynamic optimal corporate taxation focuses on optimal capital taxation in general equilibrium models, in which financing does not play a role (e.g., Farhi, 2009). Instead, we hold corporate taxation fixed and explore the planner's problem of subsidizing debt financing.

Our paper is also related to literature on financial policy and industrial organization. Consistent

\footnotetext{
${ }^{5}$ For wars-of-attrition with asymmetric information, see Fudenberg and Tirole (1986), who model exit in a duopoly setting, and Kreps and Wilson (1982). Recently, Hopenhyan and Squitnani (2011) consider the problem when the firms' types stochastically change over time. For an application of strategic timing games to corporate finance, see, for example, Acharya DeMarzo and Kremer (2011).

${ }^{6}$ Siegel $(2009,2010)$ studies contests in which players have multidimensional types in a setting with complete information.

${ }^{7}$ Since we introduce a social planner into the war of attrition, the paper is also broadly related to the work on optimal contest structure; see, for example, Moldovanu and Sela (2001) or Che and Gale (2003).

${ }^{8}$ See Auerbach (2002) for an extensive review of this literature.
} 
with our view, Zingales (1998) shows empirically that financially weak firms (i.e., firms with high leverage) exit sooner following an industry-wide profitability shock. In a similar vein, Kovenock and Phillips (1997) show that in concentrated industries firms undergoing large recapitalizations close more plants. Chevalier (1995) and Chevalier and Scharfstein (1996) find evidence that supermarkets undergoing LBOs invest less in future customers by raising prices, which is consistent with the theoretical work in Bolton and Scharfstein (1990). ${ }^{9}$ Our paper is also related to the literature on capital reallocations and its macro consequences, e.g., Ramey and Shapiro (1998, 2001), and Eisfeldt and Rampini (2008).

The paper is structured as follows: Section 2 introduces the baseline model. In Section 3, we establish the key monotonicity results, solve for the equilibrium debt schedule, and analyze welfare. Section 4 considers extensions and provides discussions on implementation of debt tax shield in practice. Section 5 concludes.

\section{The Model}

\subsection{Firms and Market}

We work in continuous time without discounting. Consider an industry with 2 firms, indexed by 1 and 2. Each firm is endowed with a single unit of capital, and has a privately observed productivity parameter $\theta_{i}$ drawn from $\Theta \equiv[\underline{\theta}, \bar{\theta}]$ with $\underline{\theta} \geq 0$, and a cumulative distribution function $F(\cdot)$. The density $f(\cdot)=F^{\prime}(\cdot)$ is continuous and strictly positive everywhere; we denote the hazard rate by $h(\theta) \equiv f(\theta) /(1-F(\theta))$. Firms' productivities $\theta_{i}$ and $\theta_{j}$ are independent and identically distributed. Without loss of generality, we index the more productive firm as firm 1 so that $\theta_{1}>\theta_{2}$. Productivity $\theta_{i}$ is each firm's private information.

The cash flows of a given firm depend on whether its competitor is still present in the industry. Following Bulow and Klemperer (1999), at any point in time $t$, firm $i$ produces cash flows of $-k$ if its opponent, firm $j$, has not yet exited the industry, and realizes a lump sum profit of $\theta_{i}$ when firm $j$ exits. ${ }^{10}$ We can also interpret the positive constant $k$ as a non-pecuniary externality that the presence of one firm imposes on the other firm. In the book industry example in the introduction, both firms maintain their stores simply to steal business from the other firm. Alternatively, one can consider this $k$ as a wasteful component of investment to maintain market share, for example,

\footnotetext{
${ }^{9}$ On the other hand, Brander and Lewis (1986) shows that leverage, as a commitment device, may make the ongoing competition tougher. Our model differs from this literature in that the firm's leverage choice is unobservable to the competitors.

${ }^{10}$ Consider a setting in which firms obtain flow payoffs and the disocunt rate is $r$. The profitability index is $\theta_{i} \in$ $[\underline{\theta}, \bar{\theta}]$. The fixed cost each period is $2 k$ and there is no marginal cost of production. There is a market of size $\Pi$. With two firms, the profit flow of each firm is $\frac{\Pi}{2}-2 k+r \theta_{i}$ while with one firm it is $\Pi-2 k+r \theta_{i}$. Set $\Pi=2 k$ and $r \rightarrow 0$.Then, as two firms compete, the profit flow is $-k+r \theta_{i} \rightarrow-k$, and the present value from winning is $\int_{0}^{\infty} e^{-r t} r \theta_{i} d t=\theta_{i}$.
} 
through advertising.

At any time the firm can be liquidated and the unit of capital is then redeployed to an alternative investment that yields a value of $l \geq 0$. This liquidation can involve direct disinvestment of capital, but one can also interpret the liquidation as cessation of investment activities that the firm needs in order to stay in business. Without loss of generality we normalize $l$ to zero, which also corresponds to disinvestment. For simplicity we do not allow partial liquidation.

This industry is at overcapacity: the first best allocation results in an immediate exit of the less productive firm. In our simple setting we only focus on firm surplus, and do not model the consumer side of the industry. In such a model, once a firm exits, the remaining firm may increase prices and decrease consumer surplus, which should also be a part of the welfare calculation. Our analysis carries through even if there is a wedge between firms' profits and welfare, as long as the first best allocation is that only one firm is active in the industry (see Section 3.2.3).

\subsection{Financing}

Each firm's unit of capital is initially financed entirely by equity, owned by a single party at each firm, the "equity holder." Before engaging in the war of attrition game described above, a firm can raise debt financing, a stage that we call "the financing stage."

Debt is available from competitive banks who, unlike competitors, observe firms' types. This is consistent with the idea that the bank will perform thorough due diligence once it establishes a financing relationship with the firm. From the theoretical point of view, this assumption allows us to focus on the basic friction in the model, which is the firm's private desire for excess continuation in the war of attrition. We relax this information assumption in Section 4.3 and show the key qualitative results still hold.

Debt is in the form of a callable bullet loan with face value $b \geq 0$ : the loan continuously rolls over and the bank can decide if it wants to collect $b$ at any point in time. Equity has limited liability, and can decide to default and leave the firm to the bank at any point in time. The bank cannot run the firm in the current industry and redeploys the capital to alternative investment. ${ }^{11,12}$ These assumptions imply that as long as both firms are in the industry the bank will keep rolling the debt over, and the equity holder defaults whenever she decides to exit the industry.

The tax rate is $\pi \in(0,1)$. Our focus is the government's tax subsidy for debt financing relative to equity financing for a given level of overall corporate taxation-we do not want the subsidy to affect the overall after-tax cash flows of the firm. We therefore fix after-tax cashflows: the fighting

\footnotetext{
${ }^{11}$ In other words, we invoke the standard assumption that bankruptcy reduces the actual productivity of the firm: as the bank takes over, it does not, for example, have the human capital required to run the firm efficiently.

${ }^{12}$ Cutting back investment rather than redeploying, is the key driver of our model. Therefore, our model applies even if the corporate form of financially distressed company survives under Chapter 11, as long as the bankruptcy procedure results in capacity cuts (see, for example Borenstein and Rose, 2003).
} 
cost $-k$, the winning cash flow $\theta_{i}$, and the debt payment of the firm $b$ are all in after-tax dollars. ${ }^{13}$ By doing so, changing the tax rate $\pi$ only affects the level of debt subsidies, but not the firm's cash flows. Thus given the after-tax debt payment $b$, the bank receives $b /(1-\pi)$. Effectively, for every one dollar received by the bank, the government contributes $\pi$ dollars and the firm pays $1-\pi$ in after tax terms.

\subsection{Equilibrium}

We study symmetric pure strategy perfect Bayesian equilibria of the game. Firms first choose debt financing and then engage in a war of attrition exit game in which firms have a two-dimensional type. The first dimension is the exogenously given productivity $\theta$. The second dimension is the amount of debt $b$, which is endogenously determined.

\subsubsection{Equilibrium debt schedule and equilibrium exit strategy}

Consider firm $i$ with type $\theta_{i}$. The information that arrives as time passes is whether its opponent, firm $j$, had exited up to this point. Throughout, we say that firm $i$ follows exit strategy $t$ (exits at $t$ ), when it chooses to exit at $t$ if firm $j$ has not exited at $t^{-}$, with $t^{-} \equiv \lim _{s \uparrow t} s$ as the left limit of $t .{ }^{14}$ Firm $i$ 's optimal exit time depends on its productivity $\theta_{i}$ its debt burden $b_{i}$. More importantly, as is standard in a war of attrition game, the firm's exit time also depends on the exit strategy of firm $j$, which we denote by $T_{j}$. From the perspective of firm $i$ who does not observe opponent $j$ 's productivity nor its debt choice, the sufficient statistic for firm $j$ 's strategy is the distribution of firm $j$ 's exit time, which is denoted by $G^{j}(t) \equiv \operatorname{Pr}\left(T_{j}<t\right)$. We can write firm $i$ 's optimal exit strategy as $T\left(\theta_{i}, b_{i} ; G^{j}(\cdot)\right)$.

In any symmetric equilibrium, $G^{j}(\cdot)=G(\cdot)$. Let $B(\cdot): \Theta \rightarrow \mathbb{R}^{+}$denote the equilibrium debt schedule, so that the firm with productivity $\theta_{i}$ borrows $B\left(\theta_{i}\right) \geq 0$ in equilibrium. The distribution of (the opponent's) exit time depends on the effective strength of all potential opponents, which in turn depends on the equilibrium debt schedule $B(\cdot)$. From now on we write $T\left(\theta_{i}, B\left(\theta_{i}\right) ; B(\cdot)\right)$ as firm $i$ 's equilibrium exit time strategy. Due to symmetry, $T(\theta, B(\theta) ; B(\cdot))$ is also the equilibrium exit strategy of its opponent $j$ with type $\theta$, and we have in equilibrium

$$
G(t)=\operatorname{Pr}(T(\theta, B(\theta) ; B(\cdot))<t) .
$$

\footnotetext{
${ }^{13}$ Given the tax rate $\pi$, the before-tax fighting cost is $k /(1-\pi)$, before-tax winning cash flow is $\theta_{i} /(1-\pi)$ and debt payment $\frac{b}{1-\pi}$.

${ }^{14}$ The left-limit definition implies that the firm exiting decision only depends on the information set right before $t$. Intuitively, if both firms set exiting strategy $t$, then both firms will exit. This treatment plays a role when firm $j$ 's strategy is such that, from firm $i$ 's perspective, it places a positive probability mass of exiting at $t$. We show that in equilibrium this never occurs so this treatment is innocuous.
} 
Two points are note-worthy regarding Eq. (1). First, in general $T$ might be non-monotone in firm's productivity $\theta$ : more productive firms may exit sooner then some less productive firms. Formally, $G(t)$ may be an integral of disconnected intervals and may involve jumps. Second, Eq. (1) embeds a fixed-point relation, as $G(t)$ enters $T(\cdot, \cdot ; \cdot)$ on the right hand side through the equilibrium debt schedule $B(\cdot)$-the equilibrium exit times are a function of the debt schedule, which, in turn, is a function of equilibrium exit times.

\subsubsection{Equity holder's problem: war of attrition stage}

We carry out our analysis backwards by first studying the war of attrition game. The payoff to equity from a firm with productivity $\theta$, which has chosen debt $b$, and exits at time $t$ has a payoff of

$$
E(\theta, b, t)=\underbrace{(1-G(t))(-k t)}_{\text {Firm exits before opponent }}+\underbrace{\int_{0}^{t}((\theta-b)-k x) d G(x)}_{\text {Firm survives after opponent exits }} .
$$

The first term captures the event where the firm loses the war of attrition: with probability $1-G(t)$ its opponent exits after $t$, and the equity holder loses $k$ continuously until $t$. The second term captures the event where the firm wins the war of attrition. If the opponent exits at time $x$, the equity holder's value is its payoff from winning, $\theta$, minus the debt that is now due, $b$, and minus the realized cost of fighting $k x$.

$$
(\theta-b)-k x \text {. }
$$

The second term in (2) integrates over the opponent's exit time $x \in[0, t]$ according to the distribution $G(\cdot)$. The equity holder chooses exit time to maximize the value of equity during the war of attrition:

$$
T(\theta, b ; B(\cdot))=\arg \max _{t \geq 0} E(\theta, b, t) .
$$

\subsubsection{Debt pricing in the first financing stage}

As is standard (e.g., Leland, 1994), firms cannot commit to a particular exit strategy. The bank therefore infers a firm's expected default time from its productivity and its choice of debt. Banks' ex post payoff depends on the before-tax promised debt payment $b /(1-\pi)$, and the probability of repayment. If the firm defaults it is liquidated for 0 , so repayment occurs only when the other firm exits. Therefore the probability of repayment is $G(T(\theta, b ; B(\cdot)))^{15}$ and the bank's expected payoff, which is also the competitive debt price, is

$$
D(\theta, b)=G(T(\theta, b ; B(\cdot))) \frac{b}{1-\pi} .
$$

\footnotetext{
${ }^{15}$ Suppose that the firm takes the exiting strategy $t$, but $G(t)$ features a jump so that $G(t)<G\left(t^{+}\right)=\lim { }_{s \downarrow t} G(s)$ which implies that there is a positive mass of probability that the opponent will exit at $t$ as well. Since we take the convention that the firm $i$ exits according to information at $t^{-}$, the chance of survival is $G(t)=\operatorname{Pr}\left(\widehat{T}_{j}<t\right)$.
} 
There are two implicit assumptions underlying this debt value expression. First, each bank finances only one firm for whom it knows the productivity through due diligence; it does not observe the opponent's productivity nor their debt choice. We relax this information assumption in Section 4.3. Second, we have assumed that $\theta>b$ so that the debt is paid in full once the opponent exits. In other words, firms never borrow more than their own productivity, a property that always holds in equilibrium (Lemma 2).

\subsubsection{Equity holders' problem in the financing stage}

The equity holder chooses the debt of firm $\theta$ to maximize her total wealth at the financing stage, which consists of the price obtained for issuing debt $b$ (4) as well as her equity value (2). The equilibrium level of debt, $B(\theta)$ then solves the following problem:

$$
B(\theta)=\underset{b \geq 0}{\arg \max } G(T(\theta, b ; B(\cdot))) \frac{b}{1-\pi}+E(\theta, b, T(\theta, b ; B(\cdot))) .
$$

Because a firm cannot commit to an exit strategy the debt choice $b$ influences the firm's ex-post exit strategy $T(\theta, b ; B(\cdot))$, which feeds back into the competitive debt price paid by banks.

\subsubsection{Definition of equilibrium}

The equilibrium in this model consists of the debt schedule $B(\cdot)$ and the exit time strategy $T(\cdot, \cdot ; B(\cdot))$ so that competitive banks earn zero profits, i.e., (4) holds; and the equity holder in each firm maximizes her value in each stage, i.e., (3) and (5) hold. Note that for each firm, the conjectured opponent's exit time distribution has to be consistent with the equilibrium debt schedule and the equilibrium exit strategy, i.e., (1) has to hold.

\section{Equilibrium with Subsidized Debt}

In this section we first show that in equilibrium more productive firms are always stronger in the war of attrition, even accounting for their choice of debt. This critical property allows us to solve for the equilibrium exit times, the equilibrium debt schedule and welfare implications of the model.

\subsection{Equilibrium Debt Schedule and Exit Times}

\subsubsection{Monotone effective strength}

We define a firm's "effective strength" as the payoff from winning the war of attrition net of debt payments, $\theta-b$. From (2) we see that it is effective strength that determines the payoff from the 
war of attrition and therefore drives differences in firms' exit times. The next lemma shows that the firm with greater effective strength exits later.

Lemma 1 The equilibrium exit time $T(\theta, b ; B(\cdot))$ is a function of effective strength $\theta-b$ only, so we denote $T(\theta, b)$ by $T(\theta-b)$. $T(\cdot)$ is increasing, and strictly increasing when $G(T(\cdot)) \in$ $(0,1)$.

Proof. See Appendix A. .

To see the intuition, which is similar to Bulow and Klemperer (1999), assume that $G(t)$ is differentiable with density $G^{\prime}(t)=g(t) ;{ }^{16}$ then, from (2), the marginal benefit to equity from staying longer is $g(t)(\theta-b)$. Because the marginal benefit is strictly increasing in $\theta-b$, firms with a higher effective strength $\theta-b$ have an incentive to exit later. Of course, once a firm is certain to win the war, $G(T(\theta-b))=1$, then increasing effective strength does not affect its exit time and vice versa for $G(T(\theta-b))=0$.

From now on, for simplicity, we denote $T(\theta, b)$ by $T(\theta-b)$. The next lemma is the central result in this section:

Lemma 2 In equilibrium, a firm's effective strength in the war of attrition $\theta-B(\theta)$ is strictly increasing in $\theta$.

Proof. See Appendix A. .

To see the intuition, let us first express the firm value from (5) using Lemma 1 such that only the effective strength $\theta-b$ enters equity value and exit time:

$$
V(\theta, b)=G(T(\theta-b)) \frac{b}{1-\pi}+E(\theta-b, T(\theta-b)) .
$$

Consider two firms $\theta_{1}>\theta_{2}$ that have the same effective strength in equilibrium, $\theta_{1}-B\left(\theta_{1}\right)=$ $\theta_{2}-B\left(\theta_{2}\right)$ and compare their incentives to marginally increase debt. First, the marginal impact of increasing $b$ on equity value $E$ in (6) is the same for both firms because of equal effective strength. The marginal impact of increasing $b$ on debt value is

$$
G(T(\theta-b)) \frac{1}{1-\pi}-G_{b}(T(\theta-b ; B(\cdot))) \frac{b}{1-\pi} .
$$

The first term is again the same for both types. Consider the second term: the firms have the same effective strength, and $\theta_{1}>\theta_{2}$ so the more productive firm borrows more, $B\left(\theta_{1}\right)>$ $B\left(\theta_{2}\right)$; further, increasing debt leads to earlier exit, lowering the probability of winning, so $G_{b}(T(\theta-b ; B(\cdot)))<0$. The second term therefore shows that the less productive firm has

\footnotetext{
${ }^{16}$ We show that $G(t)$ is strictly increasing (Lemma 5 in Appendix A) and differentiable in $t$ (Lemma 1),i.e. $g(t)$ exists and is strictly positive.
} 
strictly higher incentives for increasing debt, since a small decrease in the probability of winning causes a smaller drop in the price of its debt. At the equilibrium choice of effective strength for the more productive firm, the less productive firm wants to increase its debt burden and lower is effective strength.

\subsubsection{Equilibrium exit times}

Lemma 2 shows that, in equilibrium, from a given firm's point of view its opponents type becomes effectively one dimensional. This greatly simplifies the analysis: we can work directly with the underlying distribution of productivity $\theta$, rather than integrating over two dimensions of opponent's type $(\theta$ and $b)$. Given any potential equilibrium debt schedule $B(\cdot)$, we can characterize exit times along the lines of Bulow and Klemperer (1999), with modifications to account potential discontinuities in $B(\cdot) \cdot{ }^{17}$

Combining Lemma 1 and Lemma 2, we know that the equilibrium exit time is strictly increasing in firm's productivity. We can therefore define the equilibrium exit time $\widehat{T}(\theta ; B(\cdot))$ only as a function of underlying productivity, which is characterized by the next proposition.

Proposition 1 The equilibrium exit time $T(\theta, B(\theta) ; B(\cdot))$ is strictly increasing in $\theta$. Given an equilibrium debt schedule $B(\cdot)$, the equilibrium exit time is

$$
\widehat{T}(\theta ; B(\cdot)) \equiv T(\theta-B(\theta) ; B(\cdot))=\int_{\underline{\theta}}^{\theta} h(y) \frac{y-B(y)}{k} d y .
$$

Weaker firms always exit earlier than stronger firms, i.e., $\widehat{T}(\theta ; B(\cdot))$ is strictly increasing in $\theta$. And, in equilibrium the cumulative distribution function for exit time $G(t)=F\left(\widehat{T}^{-1}(t)\right)=$ $\operatorname{Pr}\left(\theta<\widehat{T}^{-1}(t)\right)$.

Proof. See Appendix A. .

The see the intuition behind (7) consider the decision of type $\theta$ to fight a bit longer $(d \widehat{T}(\theta))$. The cost of fighting is $k d \widehat{T}(\theta)$. The benefit is that the opponent may exit over that interval, and the firm reaps the benefit of $\theta-B(\theta)$. The exit times are strictly monotonic in productivity, and the equilibrium is symmetric. Then the conditional probability of an opponent's exit, if she has not exited up to this point, is the hazard rate $h(\theta) d \theta$ from the productivity distribution. To equate marginal cost with marginal benefit so that $k d \widehat{T}(\theta)=(\theta-B(\theta)) h(\theta) d \theta$, the optimal exit time satisfies:

$$
\frac{d \widehat{T}(\theta)}{d \theta}=h(\theta) \frac{\theta-B(\theta)}{k}
$$

\footnotetext{
${ }^{17}$ The modification can be economically relevant. While $B(\cdot)$ is continous in the main model, there are discontinuities in $B(\cdot)$ along the equilibrium path in the extension presented in Section 4.3 in which a firm's productivity is neither observable to its opponent nor to its financing bank.
} 
To obtain the exit time $\widehat{T}(\theta)$, we integrate the marginal times for firms that exit before type $\theta$, and the integration starts from $\underline{\theta}$ who sets $\widehat{T}(\underline{\theta})=0$.

Proposition 1 shows the effect of the equilibrium debt schedule $B(\cdot)$ on exit times. As we can see in (8), higher debt reduces the payoff from winning the war, thereby inducing faster exit for each individual firm. This direction of distortion is essentially the same as the debt overhang effect in Leland (1994). ${ }^{18}$ More interestingly, increasing debt for a given type decreases exit times for all higher types, because exit times are cumulative.

\subsubsection{Equilibrium debt schedule}

We now solve for the equilibrium debt schedule, which is one of the central results of the paper. For exposition purposes we heuristically derive the firm's first order condition (FOC) for choosing debt. A rigorous treatment is provided in the proof of Theorem 1 in Appendix A.

First, we study the direct effect of marginally increasing $b$ by fixing the exit time at the equilibrium level $T(\theta-B(\theta))$. Issuing more debt leads to an increase in debt and a decrease in equity value. Without a tax subsidy these two forces exactly cancel out, because, for a given exit time, $b$ only affects the allocation of firm value between equity and debt in the spirit of Modigliani and Miller (1958). With a tax subsidy the direct effect is positive as a higher debt burden increases the subsidy. This is the marginal benefit of debt, $M B$. Since the total tax subsidy is $\frac{\pi b}{1-\pi} G(t)=\frac{\pi b}{1-\pi} F(\theta)$, the marginal benefit is

$$
M B=\frac{\pi}{1-\pi} F(\theta) .
$$

This direct positive effect is the main force through which the subsidy increases equilibrium debt levels.

Second, we study the indirect effect of increasing debt due to the endogenous change of exit time $T(\theta-b)$. Lemma 1 shows that increasing $b$ shortens a firm's exit time, i.e., $T^{\prime}(\theta-b)>0$. Because exit time is chosen to maximize equity value, the envelope theorem suggests zero firstorder change in equity value in (2) from a marginal change in exit time. However, a lower exit time $T$ has a negative first-order impact on debt value $D=\frac{b}{1-\pi} G(T(\theta-b))$, because the probability of winning the war declines. This is the marginal cost of increasing debt:

$$
M C=\frac{b}{1-\pi} \frac{d G(T(\theta-b))}{d b}<0
$$

\footnotetext{
${ }^{18}$ In the literature on debt-induced distortions, equity with a close-to-zero value may want to gamble for resurrection, since its payoff is convex in realized firm value at this point. Under this "risk shifting" setting, debt may induce inefficient delay, if delay leads to riskier payoff than exit. Interestingly, our model already has a built-in possibility for such risk shifting, since staying in the industry yields a stochastic payoff, while exiting yields deterministic payoffs. The driving force in our model is that future debt payments reduce the payoffs from winning the gamble. This force dominates risk shifting, and firms financed with debt unambiguously exit earlier.
} 
Relative to the marginal benefit in (9), the marginal cost in (10) is more complicated: the decrease in exit time potentially depends on the distribution of the opponent's equilibrium exit time $\widehat{T}(\cdot ; B(\cdot))$, which in turn depends on the underlying productivity distribution and the equilibrium debt schedule $B(\cdot)$.

To calculate the marginal cost in (10) we use the insight from Proposition 1 that the probability of winning the war of attrition only depends on where a firm ranks in the distribution of effective strength. This allows us to compute (10) without relying on the equilibrium exit time $\widehat{T}(\cdot ; B(\cdot))$. We calculate how a small increase in debt changes the ranking of firm $\theta$. Increasing $b$ marginally from $B(\theta)$ by $\epsilon>0$ lowers the firm's effective strength from $\theta-B(\theta)$ to $\theta-B(\theta)-\epsilon$. We can find a type $\theta(\epsilon)$ whose equilibrium effective strength is exactly $\theta-B(\theta)-\epsilon,{ }^{19}$ so that

$$
\theta(\epsilon)-B(\theta(\epsilon))=\theta-B(\theta)-\epsilon \Rightarrow \theta(\epsilon)=\theta-\frac{\epsilon}{1-B^{\prime}(\theta)} .
$$

Therefore increasing debt by $\epsilon$ changes the relative ranking by $\frac{\epsilon}{1-B^{\prime}(\theta)}$. This is intuitive: if the slope of equilibrium schedule $B^{\prime}(\theta)$ is close to one, then, in equilibrium, firms' effective strength $\theta-B(\theta)$ increases slowly in $\theta$. Increasing debt above the equilibrium level even by a small amount will cause a large decline in ranking of effective strength in the war of attrition.

To further translate the decrease in ranking into the marginal reduction of winning probability, we need to multiply this impact by the density of opponents $f(\theta)$. As a result, the marginal cost in (10) can be alternatively expressed in a more intuitive way:

$$
M C=\frac{B(\theta)}{1-\pi} \frac{f(\theta)}{1-B^{\prime}(\theta)} .
$$

Equating the marginal benefit in (9) with the marginal cost in (11), the equilibrium debt schedule must satisfy:

$$
\pi F(\theta)=\frac{B(\theta) f(\theta)}{1-B^{\prime}(\theta)} .
$$

The closed-form solution to this differential equation (12) characterizes the equilibrium debt schedule based on the primitives of the model in the next theorem. We further establish the uniqueness of the equilibrium debt schedule, and show that there are no profitable global deviations from the debt schedule characterized by the first order condition in (12).

Theorem 1 There exists a unique symmetric pure strategy perfect Bayesian equilibrium. The equilibrium debt schedule is

$$
B(\theta)=F(\theta)^{-\frac{1}{\pi}} \int_{\underline{\theta}}^{\theta} F(y)^{\frac{1}{\pi}} d y
$$

\footnotetext{
${ }^{19}$ From continutiy of $\theta-B(\theta)$ (see proof of Lemma 1 ) we know that such a type exists.
} 
with $B(\underline{\theta})=0$ and $B(\theta)<\theta$ for $\theta>\underline{\theta}$. In the war of attrition stage, the equilibrium exit times are given by (7) in Proposition 1, with $B(\cdot)$ given in (13).

Proof. See Appendix A.

We present a sketch of the proof, which demonstrates that firms do not want to deviate globally from the equilibrium debt levels, (13), so that the FOC given in (12) is a sufficient condition for equilibrium existence. We want to show that whenever the debt level exceeds the equilibrium given in (12), $b(\theta)>B(\theta)$, the firm can profitably increase its value $V(\theta, b)$ (see (6)), by reducing its debt, i.e. $V_{b}(\theta, b)<0$. Consider $\theta^{\prime}$ with $B\left(\theta^{\prime}\right)$ which has the same effective strength as $\theta$ with debt $b(\theta), \theta^{\prime}-B\left(\theta^{\prime}\right)=\theta-b(\theta) .{ }^{20}$ Lemma 2 shows that effective strength is increasing in underlying productivity, which implies that $\theta^{\prime}<\theta$ and consequently, $b(\theta)>B\left(\theta^{\prime}\right)$. We compare the marginal impact of increasing debt, $b$, on firm value for these two firms. Since $B\left(\theta^{\prime}\right)$ is an equilibrium choice of $\theta^{\prime}$, FOC implies that $V_{b}\left(\theta^{\prime}, B\left(\theta^{\prime}\right)\right)=0$. Just as in Lemma 2, because of the same effective strength, the only difference in the impact of changing $b$ on firms' values comes from the indirect effect on the value of debt, $G_{b}(T(\theta-b ; B(\cdot))) b<0$. Because $b(\theta)>B\left(\theta^{\prime}\right)$ this implies that $V_{b}(\theta, b)<V_{b}\left(\theta^{\prime}, b^{\prime}\right)$. Therefore, if firm $\theta$ chooses $b(\theta)>B(\theta)$ it can profitably reduce its debt towards the equilibrium level $B(\theta)$. The argument for setting $\widetilde{b}$ below the equilibrium level $B(\theta)$ is analogous. Q.E.D. .

\subsection{Welfare Implications}

In general, a debt tax subsidy could affect welfare in our model through two distinct channels. The first is through sorting conditional on firm exit, i.e. if a firm exits, is it the relatively less productive firm that leaves the industry? Second, even if weaker firms exit first, so that sorting is efficient, how long is the socially wasteful war of attrition? In this section we analyze how the debt subsidy affects these two dimensions of welfare.

\subsubsection{Efficient sorting property with endogenous financial strength}

We first discuss whether sorting conditional on exit is efficient. In other words, whether it is the relatively low productivity firms that exit first. In a standard asymmetric information war of attrition without debt financing, sorting is efficient (see Fudenberg and Tirole, 1986; Bulow and Klemperer, 1999).

That sorting should be efficient is not obvious in our model. When firms enter the war of attrition game, their strength has two dimensions: their exogenous productivity $\theta$ and their endogenous debt $B(\theta)$. A priori, once debt is subsidized, the equilibrium effective strength in the war of attrition need not be monotone in the underlying productivity. If more productive firms

\footnotetext{
${ }^{20}$ From continutiy of $\theta-B(\theta)$ (see proof of Lemma 1 ) we know that such a type exists.
} 
borrow too much, it is possible that they are effectively weaker than less productive firms. In fact, a casual argument would suggest that more productive firms should take on more debt: Because they can borrow to achieve the same effective strength, they are able to enjoy greater tax subsidies. Under this logic, it may be possible to violate efficient sorting. ${ }^{21}$ However, Proposition 1 guarantees sorting efficiency in our model: More productive firms never "over borrow" relative to less productive firms, and therefore in equilibrium less productive firms always exit earlier. As a result, conditional on firm exit, it is the less productive firm that exits in equilibrium

\subsubsection{Debt tax subsidy and exit times}

The previous section implies that welfare only depends on how soon the relatively less productive firm exits the industry. This section studies the effect of the debt tax subsidy on firms' exit times.

The following proposition serves as a benchmark. Without a tax subsidy $(\pi=0)$ firms will not take on debt in equilibrium, and less productive firms exit too late relative to the first best.

Proposition 2 Without a tax subsidy $\pi=0$, the unique equilibrium is all-equity financing, $B(\theta)=$ 0 for all $\theta$. As a result, the equilibrium exit times are

$$
\widehat{T}(\theta)=\int_{\underline{\theta}}^{\theta} h(y) \frac{y}{k} d y .
$$

Proof. See Appendix A. .

With a positive debt tax subsidy, in equilibrium firms take on debt consistent with Theorem 1, which shortens exit times:

Corollary 1 The debt schedule $B(\theta ; \pi)$ is strictly increasing and exit times $\widehat{T}(\theta ; B(\cdot ; \pi))$ are strictly decreasing in the tax subsidy $\pi$ for all $\theta>\underline{\theta}$.

Proof. See Appendix A. .

When the debt tax subsidy increases, every firm has an incentive to take on a bit more debt. This direct effect is reinforced in equilibrium: Theorem 1 shows that any increase in debt by a given firm also has an indirect effect on increasing the debt level of all firms with higher productivity; we will come back to this upward spillover effect in Section 3.2.3. As debt reduces firms' effective strength, the tax subsidy shortens exit times.

\footnotetext{
${ }^{21}$ More specifically, highly productive firms may borrow a lot and take a chance that their opponent is weak enough. However, they may be unlucky, draw a moderately productive opponent who took on less debt and lose the war of attrition to that opponent.
} 
Subsidizing the equity-debt conflict of interest of weaker firms The heart of the above argument is that debt induces the well-known conflict of interest between equity- and debt-holders (e.g., Jensen and Meckling, 1976; Leland, 1994). A debt financed firm defaults earlier than it would otherwise, because equity does not internalize the losses to the bank in the war of attrition stage. Because debt is priced competitively, the equity holder at the financing stage internalizes any cost that it imposes on debt during the war of attrition stage. If there is no tax subsidy, debt financing reduces equity holders' value in the financing stage by distorting exit times in the war of attrition. Without a subsidy, the equity holder minimizes the conflict of interest by not borrowing.

A debt tax subsidy encourages firms to take on debt, and therefore intensifies this conflict of interest between debt and equity. The proponents of abolishing the subsidy argue that this conflict is costly for firms, and therefore subsidizing it is welfare destroying. In our setting, on the other hand, this conflict of interest shortens a wasteful war of attrition. Firms do not internalize this benefit, which accrues to the opponent who wins the war. Thus, a debt subsidy is required to encourage the equity-debt conflict of interest, which improves welfare in overcapacity industries. Therefore, in contrast to most of the previous literature, we emphasize that the equity-debt conflict of interest can be socially desirable, and may warrant a subsidy.

\subsubsection{Optimallity of positive debt tax subsidy}

Now we study the effect of the debt tax subsidy on welfare. We start by computing the surplus to a firm with productivity $\theta$. We first compute the expected fighting costs, which have two components. First, if the opponents are weaker, $y<\theta$, the firm incurs a total fighting cost of $k \widehat{T}(y ; B(\cdot))$ as the opponent $y$ exits at $\widehat{T}(y ; B(\cdot))$. This gives an expected cost of

$$
\begin{aligned}
\int_{\underline{\theta}}^{\theta} k \widehat{T}(y, B(\cdot)) f(y) d y & =-k \int_{\underline{\theta}}^{\theta} \widehat{T}(y, B(\cdot)) d(1-F(y)) \\
& =-k \widehat{T}(\theta, B(\cdot))(1-F(\theta))+\int_{\underline{\theta}}^{\theta} f(y)(y-B(y)) d y,
\end{aligned}
$$

where the second equality uses (7) and integration by parts. Second, with probability $1-F(\theta)$ the opponent is stronger, and the firm $\theta$ 's fighting cost of $k \widehat{T}(\theta, B)$ is a deadweight loss. Adding this cost to (15) the total expected fighting cost is simply $\int_{\underline{\theta}}^{\theta} f(y)(y-B(y)) d y$.

On the other hand, firm $\theta$ generates a positive payoff only if its opponent $y$ is weaker, which is $\int_{\underline{\theta}}^{\theta} \theta f(y) d y$. Summing up the costs and benefit, the surplus of firm $\theta$ is

$$
s(\theta, B(\cdot))=\int_{\underline{\theta}}^{\theta} f(y)[\theta-(y-B(y))] d y,
$$

where $B(y)$ is given in (13) in Theorem 1. This expression transparently illustrates the effect of debt on equilibrium welfare. A higher debt schedule $B(\cdot)$ decreases exit times, which im- 
proves equilibrium welfare in a particularly simple way. In the first best allocation the weaker firm exits immediately, and firm $\theta$ 's expected surplus $\int_{\underline{\theta}}^{\theta} f(y) \theta d y$ can be viewed as the integration of productivity $\theta$ over all weaker opponents $y \in[\underline{\theta}, \theta)$. The expression for surplus in (16) is similar, but each weaker opponent $y$ also imposes a dead weight $\operatorname{cost}$ on $\theta$ through their effective strength $y-B(y)$. The higher the debt schedule, the lower the effective strength of weaker opponents, the higher the welfare.

The total expected social surplus $S$ is an integration of individual firm surplus $s(\theta, \pi)$ over all types:

$$
S=\mathbb{E}_{\theta}\left[\int_{\underline{\theta}}^{\theta} f(y) s(y, B(\cdot)) d y\right] .
$$

The following proposition formally shows that subsidizing debt increases welfare. This result is straightforward at this point: Eq. (16) shows that higher debt levels lead to higher welfare. Increasing the subsidy $\pi$ raises the equilibrium debt schedule (Corollary 1), therefore increasing welfare.

Proposition 3 The expected social surplus $S(\pi)$ is strictly increasing in debt subsidy $\pi$, i.e., $S^{\prime}(\pi)>0$.

Proof. See Appendix A. .

The impact of the debt subsidy $\pi$ on total surplus $S(\pi)$ is at work through two distinct upward spillover forces: the first operates through equilibrium exit times, and the second through the equilibrium debt schedule. Consider the following thought experiment in which only firm $\theta$ obtains a higher debt subsidy $\pi$, which induces it to borrow a bit more. First, holding the rest of the debt schedule fixed, welfare increases for all firms that are more productive than $\theta$-notice that a weaker firms' borrowing enters in the welfare of more productive firms in (16). This is due to the bottom-up cumulative feature of equilibrium exit times in (7). The second upward spillover effect is on the equilibrium debt schedule, because a higher debt by $\theta$ increases the borrowing of all types above $\theta$ from Theorem 1 . The total welfare effect of a higher subsidy will be the full interaction and amplification of these two forces. Finally, keep in mind that our thought experiment only changed the subsidy for firm $\theta$. When we consider the impact of the subsidy on welfare in Proposition 3, $S^{\prime}(\pi)$, it is all firms that experience the increase.

While we do not model the product market, it is useful to discuss whether our welfare results are robust to a modification in which consumer surplus decreases when a firm exits the industry, either because of increased market power of the remaining firm, or smaller availability of differentiated products. Our analysis carries through even if there is a wedge between firms' profits and welfare, as long as the first best allocation is that only one firm is active in the industry. ${ }^{22}$

\footnotetext{
${ }^{22}$ Suppose that total welfare, including consumer surplus, during the war of attrition is $-2 \kappa, \kappa>0$, and wel-
} 
In some way, the result that welfare is increasing in the debt subsidy $\pi$ is not surprising. Our model is designed to highlight the social benefits of debt only; we have intentionally ignored the associated social costs, which have been better understood in the literature heretofore. In an extension in Section 4.2 we show that this result critically hinges on the fact that the industry has experienced a permanent shock to either demand or technology and never recovers. If, on the other hand, distress is temporary, and the industry might recover, then debt might also generate welfare costs in our model.

\subsection{A Special Class of Distribution}

The equilibrium debt schedule takes a simple linear form for a class of productivity distribution functions. Consider $\Theta=[0, \bar{\theta}]$ and $F(\theta)=\lambda \theta^{\alpha}$, where $\alpha>0$ and $\lambda=\bar{\theta}^{-\alpha} \cdot{ }^{23}$ This family of distribution functions nests the uniform distribution at $\alpha=1$. Using (13), firms take a debt that is a constant fraction of their productivity:

$$
B(\theta)=\frac{\pi}{\alpha+\pi} \theta .
$$

Consequently each firm's effective strength $\theta-B(\theta)=\frac{\alpha}{\alpha+\pi} \theta$ is also a fraction of its productivity. The surplus generated by firm $\theta$ is

$$
s(\theta, \pi)=\lambda \theta^{\alpha+1} \frac{\alpha+\pi+\pi \alpha}{(\alpha+\pi)(1+\alpha)},
$$

and the incremental welfare from subsidizing debt $\pi$ is

$$
S(\pi)-S(0)=\frac{2 \pi}{\alpha+\pi}\left(\frac{\alpha}{\alpha+1}\right)^{2} \bar{\theta}
$$

which is increasing in $\pi$. Later we use this special class of distributions in the extension with temporary distress in Section 4.2.

\section{Extensions and Discussion}

\subsection{Debt Tax Subsidy: Implementation}

We discuss how our model captures some of the richness in the IRS tax treatment of securities for tax purposes. Firms can potentially issue a wide range of securities that they could in principle

fare after the war of attrition is some function of the productivity of the surviving firm $w(\theta) \geq 0$ with $w$ being an arbitrary increasing function of $\theta$, i.e. welfare is increasing with the productivity of the surviving firm. The first best allocation in this setting is for one firm to survive. Instead of the total surplus computed in 17, the surplus is $S=\mathbb{E}_{\theta} \int_{\underline{\theta}}^{\theta} f(y)\left[w(\theta)-\frac{\kappa}{k}(y-B(y))\right] d y$ and it is straightforward to see that welfare is increasing in the debt subsidy $\pi$.

${ }^{23}$ More generally, the simple linear form holds for nonzero lower bound type $\underline{\theta}$, i.e., $F(\theta)=\lambda(\theta-\underline{\theta})^{\alpha}$ where $\alpha>0$ and $\lambda=(\bar{\theta}-\underline{\theta})^{-\alpha}$. 
claim to be debt instruments, which therefore deserve tax preferential treatment. In 1994, the IRS set forth factors that they use in determining whether a particular security is considered taxexempt. ${ }^{24}$ From these factors we infer which security features the IRS is trying to subsidize and link these to the forces in our model.

The first factor is that "there is an unconditional promise to pay a sum certain on demand or at a fixed maturity date that is in the reasonable foreseeable future." The unconditional promise means that payments cannot be state contingent. The non-state contingent nature of debt is critical in our model because it generates the correct type of conflict of interest. Suppose the firm could issue a tax-advantaged security whose payoff would be contingent on the firm's profitability; for instance, the equity security pays out (or bears) a fraction of the firm's profit (loss). Proposition 1 shows that the incentive to fight is determined by the ratio of the payoff conditional on winning the war relative to the cost of fighting. Such a state contingent tax subsidized security would allow the firm to reap the tax benefit without influencing the war of attrition at all. ${ }^{25}$

That tax-exempt debt securities must create a conflict of interest between debt and equity holders is definitely not just a coincidence. In fact, the following factors explicitly require a conflict for debt to be subsidized.

1. First, the IRS considers "whether there is identity between the holders of the instrument and stockholders of the issuer," i.e., debt should be held by a different entity than equity. If the same investor held both debt and equity in our model, she would simply maximize the (private) value of the firm, reverting back to the all equity case. ${ }^{26}$

2. Second, the IRS considers whether "the rights of the instruments are subordinate to the rights of general creditors," i.e., whether instrument holders are lower in priority of liquidation than general debt holders. Suppose the tax subsidized instrument had the same priority in bankruptcy as equity. Then equity would pari pasu participate in the liquidation of the company, ex-post bearing a part of bankruptcy cost, which would partially resolve the conflict of interest between debt and equity. Consequently, it dampens the incentive of equity holders to liquidate the firm, lengthening the war of attrition.

3. Finally, the IRS requires that the holders of debt should not have the right to participate in the management of the firm, giving equity the decision rights. If debt holders were allowed to participate in the liquidation decision in our model, they would delay liquidation, since

\footnotetext{
${ }^{24}$ IRS Notice 94-47, 1994-19 I.R.B. 1, 04/18/94.

${ }^{25}$ The firm would prefer to issue the state contingent tax prefered security over tax prefered debt because of a lower private cost of the conflict of interest.

${ }^{26}$ This factor also increases the cost of equity purchasing the outstanding debt in order to stave off bankruptcy. If equity were to purchase the outstanding debt on the open market, they would not obtain the tax subsidy.
} 
they bear the cost ex-post. This would allow equity to reap the benefits of the tax subsidy ex ante through debt pricing without shortening the war of attrition.

That the IRS subsidizes securities that create a conflict of interest between equity and debt holders, especially in regards to bankruptcy, is intriguing. Although the literature, starting from Jensen and Meckling (1976), has been emphasizing the dark side of the equity-debt conflict of interest, IRS explicitly favors this type of conflict. This seemingly odd requirement is consistent with our model. The equity-debt conflict of interest, which is at the heart of our argument, in is socially desirable, as we discuss in Section 3.2.2.

While the goal of our paper is primarily normative, these results on practical implementation of the subsidy necessarily raise the hurdle for alternative explanations of the debt tax subsidy. For example, consider an alternative explanation in which the debt tax subsidies are a result of lobbying by lenders and borrowers, who want to extract rents from the government. Then one would want to explain why rents to the intermediation sector and borrowers are maximized by this particular implementation of the subsidy.

A more sophisticated alternative explanation would be that equity holders dislike discipline from debt holders, even though it improves firm value. The government realizes that this limits borrowing by equity holders, and therefore debt needs to be subsidized. First, notice that this may not in fact be an externality. Since equity holders internalize their misbehavior ex ante when rasing debt, the role for the government is not a priori clear. Moreover, this view is inconsistent with point 3 above, in which the IRS requires that debt holders not have the right to participate in the management of the firm. If debt is subsidized to ensure monitoring of equity holders, allowing debt holders to intervene would be a good solution.

Another alternative explanation would be that debt tax subsidies exist for historical reasons. In response the IRS uses the conflict of interest to curb equity holders' borrowing and limit the amount of debt tax subsidies to the business sector. In addition to being a socially costly way to decrease rents, this view is inconsistent with point 3: allowing debt holders to intervene should be more effective in limiting equity holders' borrowing.

\subsection{Duration of distress}

In the model above we analyze an industry that has been hit with a permanent demand or technology shock, from which it can only recover by reducing capacity. In this case, subsidizing debt is always optimal and higher subsidies lead to more welfare through faster exits. Suppose instead, that the demand shock is temporary, and the industry will eventually recover to support the full capacity. In this section we study how changing the duration of industry shocks alters the role of subsidizing corporate debt financing. 
We study an industry that will eventually recover at time $T_{d}$, at which point the war of attrition exogenously terminates. If both firms persist until $T_{d}$, they each obtain their corresponding payoff $\theta_{i}$ 's. The model studied above is nested as $T_{d}$ goes to infinity.

\subsubsection{First best}

The fact that the industry recovers to support both firms at $T_{d}$ implies that it may not always be socially desirable to eliminate the weaker firm. Consider the first best allocation, and index the stronger firm with $\theta_{1}$. If both firms survive until $T_{d}$ the total surplus is $\theta_{1}+\theta_{2}-2 k T_{d}$. Alternatively, the weaker firm exits immediately and the surplus is $\theta_{1}$. Therefore, the first-best allocation is

\begin{tabular}{ll}
\hline \hline Both firms survive & if $\theta_{2} \geq 2 k T_{d}$ \\
\hline Only strong firm $\theta_{1}$ survives & if $\theta_{2}<2 k T_{d}$ \\
\hline \hline
\end{tabular}

In other words, the weaker firm should exit immediately if its productivity is below the total fighting cost in the industry until recovery, $2 k T_{d}$. The productivity threshold, at which the weaker firm should exit under first best, is increasing in the duration of distress. In our benchmark case distress is permanent $\left(T_{d}=\infty\right)$, and thus it is always socially efficient for the weak firm to exit immediately.

\subsubsection{Equilibrium characterization}

The next proposition characterizes the equilibrium of the model in which distress is temporary. There is an endogenous threshold type $\hat{\theta}$ who is indifferent between exiting before $T_{d}$ and waiting until $T_{d}$. Firms below $\hat{\theta}$ have equilibrium debt schedules and an exit times that are identical to the benchmark case with $T_{d}=\infty$. Firms above $\hat{\theta}$ never exit, and they borrow to the extent that their effective strengths equals that of the threshold type $\hat{\theta}$.

Proposition 4 In the model with a distress period $T_{d}$, the equilibrium debt schedule is

$$
B(\theta)=\left\{\begin{array}{cc}
(F(\theta))^{-\frac{1}{\pi}} \int_{0}^{\theta}(F(y))^{\frac{1}{\pi}} d y & \text { for } \theta \leq \hat{\theta} \\
\theta-\hat{\theta}+B(\hat{\theta}) & \text { for } \theta>\hat{\theta},
\end{array}\right.
$$

and the equilibrium exit times are:

$$
\widehat{T}(\theta)=\left\{\begin{array}{cc}
\int_{\underline{\theta}}^{\theta} h(x) \frac{x-B(x)}{k} d x & \text { for } \theta \leq \hat{\theta} \\
\infty & \text { for } \theta>\hat{\theta}
\end{array}\right.
$$

where the unique threshold type $\hat{\theta}$ is given by the solution to the equation

$$
k T_{d}=k \widehat{T}(\hat{\theta})+\hat{\theta}-B(\hat{\theta})
$$


And, the threshold $\hat{\theta}$ is decreasing in $\pi$ and increasing in $T_{d}$.

If a solution to 18 does not exist, $B(\theta)$ and $\widehat{T}(\theta)$ are given by the benchmark model.

Proof. See Appendix B. .

To see the intuition, the equity holder's payoff given the opponent's exit time distribution $G(t)$ is

$$
E(\theta, b, t)=\left\{\begin{array}{cc}
(1-G(t))(-k t)+\int_{0}^{t}((\theta-b)-k x) d G(x) & \text { for } t \leq T_{d} \\
(\theta-b)+\int_{0}^{T_{d}}(-k x) d G(x) & \text { for } t>T_{d}
\end{array} .\right.
$$

In short, if a firm exits before $T_{d}$, her payoff is exactly the same as in the benchmark case $T_{d}=\infty$. If the firm decides to stay until $T_{d}$, however, she wins the prize $\theta$ for sure. We can follow the same argument as before to show that in the symmetric pure strategy equilibrium the exit time $\widehat{T}(\theta)$ is strictly increasing in $\theta$ (before $T_{d}$ ). Thus, there will be a threshold $\hat{\theta}$ such that firms above $\hat{\theta}$ never exit. For types below $\hat{\theta}$, the game is the same as in the benchmark model. Because the equilibrium exit of firm $\theta$ only depends on the marginal exit time of his weaker opponents, the equilibrium exit time for all types below $\hat{\theta}$ is the same as in the benchmark model.

The equilibrium debt schedule $B(\cdot)$ for $\theta<\hat{\theta}$ is also identical to the benchmark model. Any type will borrow so that the marginal benefit of debt tax shield equalizes the marginal cost of weakening herself, so the same first order condition as (12) determines the debt schedule. Firms $\theta>\hat{\theta}$ borrow the highest amount of debt such that they never exit, which equalizes their effective strength with that of $\hat{\theta}$. Finally, the equation for the threshold $\hat{\theta}$, Eq. (18), is determined from the indifference condition between exiting at $\widehat{T}(\hat{\theta} ; B)$ and staying forever for type $\hat{\theta}^{27}$

Proposition 4 shows that the debt subsidy in industries with temporary distress affects firm exit on two margins. First, increasing debt reduces exit times of firms which would have exited even if there were no subsidy. This is the intensive margin of exit, which is also present in the benchmark case in which industry distress is permanent. When industry distress is temporary, in addition to the intensive margin, subsidizing debt also affects the extensive margin of exit. As the debt tax subsidy increases debt levels, the threshold productivity $\hat{\theta}$ decreases. This induces firms, which would not have exited otherwise, into bankruptcy.

\subsubsection{Duration of distress, welfare, and an interior optimal debt subsidy}

We now explore how changing the duration of industry shocks affects the result from Proposition 3 , that increasing debt subsidies always increases welfare. We compare the allocation in Proposition 4 with the first best allocation. The planner faces a tradeoff: increasing the subsidy past the point at which $\hat{\theta}=2 k T_{d}$ has both benefits and costs. Increasing the subsidy improves the

\footnotetext{
${ }^{27}$ We show that $\hat{\theta}$ is unique and the conditions under which it exists in Appendix B.
} 

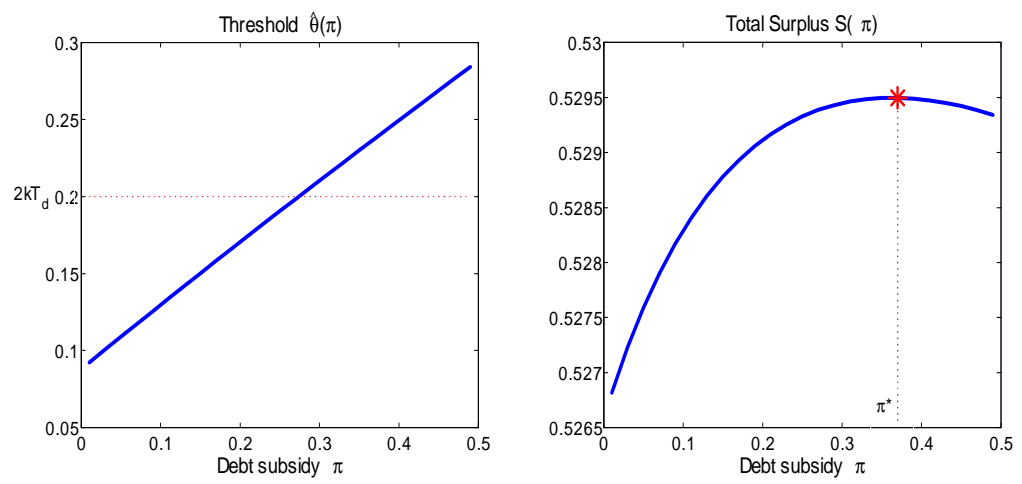

Figure 1: The extension with temporary distress. We plot the threshold type $\widehat{\theta}(\pi)$ and the total surplus $S(\pi)$ as functions of debt subsidy $\pi$. Parameters are $k=0.1, T_{d}=1, \alpha=0.2, \bar{\theta}=3.5$ so that $\lambda=0.78$.

intensive margin of exit by accelerating weaker firms' default. But it also forces the exit of firms that should not exit under the first best allocation: $\hat{\theta} \geq \theta=2 k T_{d}$.

We first argue that the welfare optimal debt subsidy is strictly positive even with eventual recovery. Without a debt subsidy firms still refrain from debt financing. The argument is similar to the benchmark case in Section 3.2.2. With only equity financing 18 , the threshold type $\hat{\theta}=$ $k T_{d}-k \widehat{T}(\hat{\theta} ; B=0)<2 k T_{d}$. Thus the planner can increase welfare on both the intensive and extensive margin by increasing the debt subsidy from 0 .

In contrast to the benchmark case, the debt tax subsidy can be too large. This occurs when the marginal benefit of increasing the intensive margin of exit is outweighed by bankrupting firms that should not have exited. Balancing these two forces then gives rise to an interior welfare maximizing debt subsidy $\pi$. We illustrate this point using the productivity distribution $F(\theta)=$ $\lambda \theta^{\alpha}$ introduced in Section 3.3. In Appendix B, we provide a closed-form expression for (18) which allows us to solve for the threshold type $\hat{\theta}(\pi)$ as a function of $\pi$. Consider the numerical example in Figure 1, where $k=0.1, T_{d}=1, \alpha=0.2, \bar{\theta}=3.5$ so that $\lambda=0.78$. The left panel graphs the threshold type $\hat{\theta}(\pi)$ against the debt subsidy $\pi$. As $\pi$ increases, firms take on more debt, and the threshold type $\hat{\theta}(\pi)$ increases, which implies that both the expected number and productivity of firms going bankrupt increases. At $\pi=0.28$ the threshold type $\hat{\theta}(\pi)$ exceeds the first-best cutoff $2 k T_{d}=0.2$. At this point the expected number and productivity of firms going bankrupt is at the first best. The optimal debt subsidy $\pi^{*}$, however, exceeds 0.28 , because weaker firms' exit times are above the first best levels. As is shown in the right panel, the social planner is willing to trade-off inefficient bankruptcy with shorter exit times and we obtain the highest welfare at $\pi^{*}=0.36$. 


\subsection{Productivity unobservable to banks}

In order to highlight the role that the war of attrition plays in our model, the benchmark model assumes that asymmetry of information about productivity is limited only to firms. In other words, a bank can observe the productivity of the firm that it is financing. In this section we show that our main results are robust to relaxing this assumption. In particular, we show that less productive firms exit first, that exit times given a debt schedule do not change, and that it is welfare maximizing to subsidize debt.

As in the benchmark model, the debt market is competitive. Firms request debt $b$ from banks, who do not observe firms' types. In this setting, the war of attrition given a debt schedule remains the same, i.e., the equity holder's objective in (2) is unchanged. There is a substantive difference in debt pricing since banks use debt choices to infer firms' productivity. Firms then try to use debt choices to manipulate this inference. Given a particular equilibrium, define the set of types that choose debt $b$ as $\Theta(b) \equiv\{\theta: B(\theta)=b\}$. Then, conditional on $b$, the exit time distribution can be summarized by

$$
F(\theta ; b) \equiv \frac{\operatorname{Pr}(y \leq \theta \mid \theta \in \Theta(b))}{\operatorname{Pr}(\theta \in \Theta(b))} .
$$

Debt value for a given type $\theta$ is $D(b ; \theta)=G(T(\theta, b ; B(\cdot))) \frac{b}{1-\pi}$ as in (4). Integrating over types conditional on $b$, the competitive price for debt $b$ is

$$
D(b)=\int_{\theta \in \Theta(b)} D(b ; \theta) d F(\theta ; b) .
$$

Firm $\theta$ chooses debt $B(\theta)$ to maximize its value at the financing stage:

$$
B(\theta)=\underset{b \geq 0}{\arg \max } D(b)+E(\theta, b, T(\theta, b ; B(\cdot))) .
$$

The equilibrium in this extension of the model consists of the debt schedule $B(\cdot)$ and the exit time strategy $T(\cdot, \cdot ; B(\cdot))$ such that competitive banks earn zero profits, i.e., (19) holds; and the equity holder maximizes her value at each stage, i.e., (3) and (20) hold.

We only present the main results from the model. We can solve the benchmark model because Lemma 2 shows that effective strength is increasing in productivity. While this relationship is preserved in this extension, the mechanism is different.

Lemma 3 When the borrower's productivity is unobservavble to banks, the equilibrium debt schedule $B(\cdot)$ is non-increasing, and in any equilibrium more productive types choose (weakly) lower debt. Therefore, a firm's effective strength in the war of attrition $\theta-B(\theta)$ is strictly increasing in productivity $\theta$.

Proof. See Appendix C. . 
The intuition for this lemma comes from truthful revelation of firms' productivity: more productive firms, which fight longer, in expectation pay more to the banks for the same choice of $b$. As servicing debt is more costly for more productive firms, they in equilibrium take (weakly) less debt. This result is stronger than the one in Lemma 2. With complete information, more productive firms try to take advantage of the debt subsidy by borrowing more, but not enough to make themselves weaker than less productive firms in the war of attrition. With asymmetric information, more productive firms take on (weakly) less debt. In other words, firms with greater productivity effectively become even (weakly) stronger in the war of attrition. This monotonicity result implies that, just as when banks observe firm productivity, subsidized debt financing does not cause inefficiencies in ex-post sorting of firms-weak firms always exit first.

Further, Lemma 3 also implies that for a given debt schedule the equilibrium exit times are closely related to Proposition 1 . The difference is that the debt schedule may affect the extensive margin of exit even if the industry never recovers. Because the debt schedule is decreasing in productivity, there could be types which obtain more debt than their productivity $\theta<B(\theta)$. These types exit immediately as they lose money even if the other firm exits first. In the benchmark model this cannot occur, since a bank is not willing to lend to a firm which defaults instantaneously. In the asymmetric information case, on the other hand, low productivity firms may be able to extract an information rent in the financing stage and then immediately default.

Lemma 4 Let $\underline{\hat{\theta}} \equiv \inf \{\theta: \theta-B(\theta)>0\}$. Then

$$
T(\theta ; B(\cdot))=\left\{\begin{array}{cl}
0 & \text { for } \theta \leq \underline{\hat{\theta}} \\
\int_{\underline{\hat{\theta}}}^{\theta} h(y) \frac{y-B(y)}{k} d y & \text { for } \theta>\underline{\hat{\theta}}
\end{array}\right.
$$

Proof. See Appendix C. .

The next proposition is the central result in this section, which shows that setting a positive tax subsidy remains optimal.

Proposition 5 We have the following results:

1. Without the tax subsidy, $\pi=0$, the unique equilibrium is all-equity financing, i.e. $B(\theta)=0$ for all $\theta$.

2. The equilibrium exit times with $\pi=0$ are

$$
T(\theta)=\int_{\underline{\theta}}^{\theta} h(y) \frac{y}{k} d y .
$$

3. The social planner chooses a positive tax subsidy, $\pi>0$. 
Proof. See Appendix C. .

The first and second results replicate Proposition 2. Without debt subsidies, firms internalize the equity-debt conflict of interest but not the war of attrition externality. Therefore they will not take on any debt in equilibrium.

In contrast to the benchmark case, debt financing has a social cost. Inducing more debt leads to inefficient liquidation if the productivity of both firms is below $\underline{\hat{\theta}}$. Then both firms are liquidated immediately, although the stronger one should have survived under first best. Nevertheless, Proposition 5 shows that for small levels of debt, this cost is always dominated by the benefit of expediting faster exits of weaker firms. Thus, a debt tax subsidy is necessary to induce a welfare maximizing level of debt.

To see the intuition, consider increasing the debt tax subsidy to induce a small increase in the debt schedule, $B(\theta)>0$. Because $B(\theta)$ is small, $\underline{\hat{\theta}}$ either equals $\underline{\theta}$ or is close to $\underline{\theta}$ because $B(\theta)$ is weakly decreasing in $\theta$. Due to the cumulative feature of exit times, the welfare gain from shortening exit times benefits almost all firms, $\theta>\underline{\hat{\theta}}$. The welfare loss, on the other hand, is very

unlikely, since both firms have to lie in the interval of $[\underline{\theta}, \underline{\hat{\theta}}]$, which is at a lower order compared to the social benefit.

The results in this section are robust to a wide class of models in which there is asymmetric information between banks and firms. For example, consider the model in which the bank is a monopolist and offers a debt schedule to firms. Lemma 3 (which relies only on truth-telling incentives of the firms), Lemma 4, and the first two results without debt subsidy in Proposition 5, are unaffected. The only part of the argument that explicitly relies on the shape of the debt schedule is the proof for the third result in Proposition 5. However, for strictly positive but arbitrarily small debt schedules, the proof proceeds along similar lines of comparing second order losses on the extensive margin and first order gains on the intensive margin.

\subsection{Coasian Solution}

In this subsection we examine a "Coasian" solution to the costly war of attrition. Specifically, we examine whether a third firm (called $C$ ) can purchase both firms in the industry, potentially close the less productive firm, and thereby internalize the cost. In that case the government does not need to use tax policy to reduce the war of attrition externality. Because firms' productivity is private information, the buyer faces an adverse selection problem. We show that adverse selection is so severe that it imposes losses on the buyer whenever she tries to internalize this externality. In other words, the Coasian solution fails so there is room for government intervention.

We first consider static unconditional bidding, and then extend this case to conditional offers and the ability of firm $C$ to make offers over time. We finish this section with a short discussion 
of mergers and acquisitions.

\subsubsection{Static bidding}

We first examine the case where firm $C$ can only make offers once. Formally, before the war of attrition, firm $C$ offers a price $p$ to both firms. Both firms decide simultaneously whether to accept the bid, which is public information. If a firm is indifferent then it accepts the bid. ${ }^{28}$ Upon purchase, $C$ learns the productivity of acquired firms and can decide whether and which firms to close. If only one firm accepts the bid, then $C$ inherits that firm's asset and competes with the other firm in the war of attrition.

Our main result is given in Proposition 6. We first establish that the equilibrium strategy of rejecting bids is monotone in firms' type. In equilibrium there exists a threshold $\hat{\theta}$, such that firms, which are more productive than $\hat{\theta}$ reject the bid and vice versa. Second, we characterize the unique pure strategy equilibrium of this game. To do so, we have to specify off equilibrium beliefs. Suppose $\theta_{i}>\hat{\theta}>\theta_{j}$. In equilibrium the strong firm $\theta_{i}>\hat{\theta}$ rejects the bid and the weak firm $\theta_{j}<\hat{\theta}$ sells its asset to firm $C$. Therefore, in equilibrium it has been revealed that $C$ owns the weaker firm, so it will exit immediately. However, on the off equilibrium path firm $C$ may enter the war of attrition. We impose the off equilibrium belief that the strong firm $\theta_{i}$, which rejected the bid, forgets that $C$ 's asset is weak, and instead behaves as though the sold firm is drawn from the distribution of firms which should have rejected the bid.

Note that this off equilibrium belief increases incentives of $\theta_{i}$ to sell the firm, improving the potential for a profitable acquisition by firm $C$, and thus favors the Coasian solution. However, even under favorable off equilibrium beliefs, and the fact that $C$ faces no competition in bidding for firms, we show that it earns strictly negative profits in situations in which any externalities are internalized, so the private solution always fails.

Proposition 6 We have the following results:

1. Given $p$, the equilibrium strategy of rejecting bids is monotonically increasing in firm type.

2. Under the off equilibrium belief specified above, given p there exists a unique pure strategy symmetric equilibrium. In this equilibrium, define the cutoff $\widehat{\theta}$ which solves $\widehat{\theta} F(\widehat{\theta})=p$. All firms below $\hat{\theta}$ accept the bid and all firms above $\hat{\theta}$ reject the bid. If both firms accept, firm $C$ closes the weaker firm. If both firms reject the bid, they compete in a war of attrition with exit times Proposition 2 truncated below at $\hat{\theta}$. If firm $i$ rejects, while firm $j$ accepts so the firm $C$ buys firm $j$, firm $C$ exits immediately (and firm $i$ stays forever).

\footnotetext{
${ }^{28}$ The result is the same if we break the tie in the other way, i.e., reject whenever indifferent.
} 
3. In any equilibrium in (2) in which firms are sold with positive probabilities, the buyer's expected profits are strictly negative.

Proof. See Appendix D. .

The results in Proposition 6 are intuitive. As firm $C$ raises its bid, it draws in marginally more productive firms, which increases the expected value of acquired firms and the probability that it internalizes the externality. Result 3 shows that this benefit is more than undone, since a price increase also accrues to less productive firms who would have accepted a lower bid as well. Therefore it is optimal for firm $C$ not to bid, and the private solution to internalize the externality between the firms breaks down.

We also consider contingent bids in which $C$ pays price $p$ only when both firms accept. One may think such offers should reduce the adverse selection problem and therefore increase the viability of a private solution to externalities. The corollary below states that that is not the case. The argument is similar to the one with non-contingent offers.

Corollary 2 In any equilibrium of a contingent offer game in which firms are sold with positive probabilities, the buyer's expected profits are strictly negative.

Proof. See Appendix D. .

\subsubsection{Time-varying bidding schedule}

The previous section considers only static offers. Now suppose that firm $C$ can offer a history dependent pricing schedule and both firms can choose to sell at any time. More specifically, firm $C$ can offer a schedule $\left\{p_{1}(\cdot), p_{2}(\cdot, \cdot)\right\}$. Each firm can be the first to sell its asset to $C$ at a price of $p_{1}(t) \geq 0$ at time $t$ or it can reject the bid; the sale is publicly observable. If there is only one firm (say $i$ ) that sells, then firm $j$ competes with firm $C$ (with asset $\theta_{i}$ ) after $t$. Firm $\mathrm{C}$ can close the firm at any time and may propose a continuation pricing offer $p_{2}(s, t) \geq 0$ for any future time $s>t$. If both firms sell to $C$ at the same time, then $C$ may close either of the acquired firms at any point in time as in the static case.

As before, if a firm is indifferent between accepting and rejecting the bid, it accepts the bid. We further require that firm $C$ employs a pricing strategy that earns nonnegative expected profits at any point in time; effectively, firm $C$ cannot commit to offer a pricing schedule that may become suboptimal (relative to withdrawing the bid) at some point in the future. ${ }^{29}$

This schedule is potentially an improvement over the static offer, because it may induce less productive firms to sell earlier at lower prices, thereby reducing the overall information rent that firm $C$ is paying. However, similar to our earlier results, Proposition 7 shows that the private

\footnotetext{
${ }^{29}$ For an example of selling with commitment, see Board and Skrzypacz (2010).
} 
solution is still not viable. We first establish that, given any possible equilibrium pricing schedule, the equilibrium time of sale is increasing in firm type. We then show that for reasonable classes of equilibria, there does not exist an equilibrium where firms are purchased with positive probability and firms earn non-negative profits.

Proposition 7 We have the following results.

1. Given $\left\{p_{1}(\cdot), p_{2}(\cdot, \cdot)\right\}$, the equilibrium time of accepting the offer is monotonically increasing in firm type.

2. In any subsequent war-of-attrition game with common knowledge that one firm is strictly stronger than the other, we restrict attention to the equilibrium outcome in which the weaker firm exits immediately. Then, in the game with time-varying offering prices and without commitment, the buyer's expected profits are strictly negative in situations in which firms are sold with positive probability.

Proof. See Appendix D. .

Here is a sketch of the argument. Given that the equilibrium time of sale is increasing in productivity, we need to consider two cases. First, suppose that two firms sell their assets at different times. Then, right after firm $i$ accepts the offer it is common knowledge that firm $j$ is more productive than firm $C$. For this subgame, we restrict attention to the equilibrium outcome where the stronger firm $j$ stays while the weaker firm $C$ exits immediately. Firm $C$ therefore incurs a loss: it pays a positive price for firm $i$ but never recoups any profit. Second, suppose that both firms accept $C$ 's offer at the same time. This situation involves a sequence of offers and different types pool over time. For example, at time $t_{1}$, types $\left[0, \theta_{1}\right]$ sell the firm, at $t_{2}$, types $\left(\theta_{1}, \theta_{2}\right]$ and so on. This game will terminate in a subgame identical to the static bidding game studied in Section 6, but with the productivity distribution truncated from below. Therefore firm $C$ incurs losses in the last subgame, which violates the no commitment requirement.

\subsubsection{Mergers and acquisitions}

A related channel to the Coasian solution are mergers and acquisitions, in which it is firms in the industry that acquire each other. Firms in the industry do not know which firm is stronger, and face a similar adverse selection problem as the outside buyer in the Coasian solution considered above. In addition, the offer itself can be used as a signal of buyer's productivity and therefore subject to manipulation, making efficient exits impossible (Cramton, 1992). Therefore it is unclear whether the possibility of acquisitions within the industry reduces information frictions relative to the Coasian solution. An explicit analysis of acquisitions necessarily involves repeated 
bargaining with asymmetric information and is nontrivial to analyze in our framework (see, for example, Fuchs and Skrzypacz, 2010, for a model with one-sided asymmetric information). To sum up, private solutions to the war of attrition face potential market breakdown due to asymmetric information, providing a rationale for government intervention with a debt tax subsidy.

\section{Conclusion}

Allowing corporations to deduct interest payments from corporate taxes is a large government subsidy to debt financing. Such subsidies are common around the world and introduce a large wedge between the cost of equity and debt (Congressional Budget Office, 2005). In spite of the role of debt financing in the recent crisis, and the magnitude of the subsidy for this financing choice, the welfare consequences of subsidizing debt have received very little attention in the literature. Contrary to practice, the theoretical literature implies that debt and equity should be treated equally, or that debt should be taxed more heavily than equity, if industries experience temporary shocks that lead to collateral based spillovers. We show that, on the other hand, when economies experience shocks that leave some industries permanently obsolete, debt financing generates welfare by facilitating efficient exit. Whether the debt subsidy should be abolished, as has been proposed several times, therefore depends on the magnitude of these costs and benefits. Beyond simply providing a rationale for subsidizing corporate debt financing, our model naturally rationalizes the seemingly ad hoc feature of the U.S. tax system that targets the subsidy at debt securities, which generate a conflict of interest between debt and equity regarding firm liquidation.

The recent financial crisis has also spurred an extensive debate on subsidizing debt financing of financial intermediaries (e.g. Admati et al, 2011; Kashyap et al, 2010). Our model does not distinguish between financial intermediaries and other firms, so it can, in principle, also be applied to financial intermediaries. Given that financial intermediaries are more vulnerable to fire sales externalities than industrial firms (Diamond and Rajan, 2010; Stein, 2011), it is more likely that in their case the cost of subsidizing debt outweighs the benefit. Our model does not speak to the optimallity of another large interest tax subsidy: the mortgage tax deduction. In our model the corporate debt tax subsidy is trying to resolve the inefficiently slow exit of firms in declining industries. It is not clear that there is a mapping from our model to residential home ownership. In fact, the current literature suggests that homeowner bankruptcy generates negative spillovers on other homeowners (e.g. Campbell, et al, 2010).

\section{References}

Acharya, V., DeMarzo, P. and Kremer, I., (2011),"Endogenous Information Flows and the Clustering of Announcements," American Economic Review, Forthcoming. 
Admati, A., DeMarzo, P., Hellwig, M., and Pfleiderer, P., (2011), "Fallacies, Irrelevant Facts, and Myths in the Discussion of Capital Regulation: Why Bank Equity is Not Expensive," Stanford GSB Research Paper, 2065.

Auerbach, Alan, (2002), "Taxation and corporate financial policy" in A. Auerbach and M. Feldstein, eds., Handbook of Public Finance, 1251-1292.

Board, S. and Skrzypacz, A., (2010), “Revenue Management with Forward-Looking Buyers,” Working paper.

Barron’s, (2005), “Book Values,” August 29.

Bolton, P., and Scharfstein, D., (1990), "A Theory of Predation Based on Agency Problems in Financial Contracting," American Economic Review, 80, 93-106.

Borenstein, S. and Rose, N., (2003), “The Impact of Bankruptcy on Airline Service Levels,” American Economic Review, 93, 415-419.

Brander, J., and Lewis, T., (1986), “Oligopoly and Financial Structure: The Limited Liability Effect,” American Economic Review, 76, 956-970.

Bulow, J., and Klemperer, P. , (1999), “The Generalized War of Attrition,” American Economic Review, 89, 175-189.

Business Week, (2011), “The End of Borders and the Future of Books,” November 10.

Campbell, J., Giglio, S., and Pathak, P., (2011), "Forced Sales and House Prices," American Economic Review, forthcoming.

Che, Y. and Gale, I., (2003), “Optimal Design of Research Contests,” American Economic Review, 93, 646671.

Chetty, Raj and Saez, Emmanuel. (2010), "Dividend and Corporate Taxation in an Agency Model of the Firm," American Economic Journal: Economic Policy, 2, 1-31.

Chevalier, J., (1995), "Capital Structure and Product-Market Competition: Empirical Evidence from the Supermarket Industry," American Economic Review, 85, 415-435.

Chevalier, J. and Scharfstein, D., (1996), "Capital-Market Imperfections and Countercyclical Markups: Theory and Evidence," American Economic Review, 86 (4), 703-725.

Congressional Budget Office, (1997), “The Economic Effects of Comprehensive Tax Reform.”

Congressional Budget Office, (2005), “Corporate Income Tax Rates: International Comparisons.”

Cramton, P,. (1992), "Strategic Delay in Bargaining with Two-Sided Uncertainty" Review of Economic Studies, 59, 205-225.

Diamond, D. and Rajan, R., (2010), "Fear of Fire Sales, Illiquidity Seeking, and the Credit Freeze”, Quarterly Journal of Economics, forthcoming.

Eisfeldt, A. and Rampini, A., (2008), "Managerial Incentives, Capital Reallocation, and the Business Cycle", Journal of Financial Economics 87, 177-19.

Fuchs, W. and Skrzypacz, A., (2010), "Bargaining with Arrival of New Traders," American Economic Review, $100(3), 802-836$.

Fudenberg, D. and Tirole, J., (1986), “A Theory of Exit in Duopoly,” Econometrica, 54, 943-960.

Graham, J., (2000), “How Big Are the Tax Benefits of Debt?” The Journal of Finance, 55, 1901-1941.

Gordon, R. and Dietz, M., (2006), "Dividends and Taxes," NBER Working Paper No. 12292.

Harris, Milton and Raviv, Artur, (1991), “The Theory of Capital Structure,” The Journal of Finance, 46, 297-355. 
Hopenhayn, H, and Squinani, F., (2011), "Preemption Games with Private Information," Review of Economics Studies, forthcoming.

Jensen, M., (1993), "The Modern Industrial Revolution, Exit, and the Failure of Internal Control Systems," The Journal of Finance,48, 831-880.

Jensen, M. and Meckling, W. , (1976), "Theory of the firm: Managerial behavior, agency costs and ownership structure," Journal of Financial Economics, 3, 305-360.

Jovonavic, B., and Tse C., (2006), “Creative Destruction in Industries,” NBER Working paper 12520.

Kashyap A., Stein, J. and Hanson, S., (2010), "An Analysis of the Impact of 'Substantially Heightened' Capital Requirements on Large Financial Institutions," Working Paper.

Kovenock, D. and Phillips, G., (1997), "Capital Structure and Product Market Behaviour: An Examination of Plant Exit and Investment Decisions," The Review of Financial Studies, 10 (3), 767-803.

Kreps, D. and Wilson, R., (1982), "Reputation and Imperfect Information,” Journal of Economic Theory, 27, 253-279.

Leland, H., (1994), “Corporate debt value, bond covenants, and optimal capital structure," Journal of Finance, 49, 1213-1252.

Lorenzoni, G., (2008), “Efficient Credit Booms,” Review of Economics Studies, 75, 809-833.

Smith, M. (1974), "The Theory of Games and the Evolution of Animal Conflicts," Journal of Theoretical Biology, 47, 209-221.

Milgrom, P. and Segal, I., (2002), "Envelope Theorems for Arbitrary Choice Sets,” Econometrica, 70, 583601 .

Modigliani, F. and Miller, M. (1958), "The Cost of Capital, Corporation Finance and the Theory of Investment," American Economic Review, 48 (3), 261-297.

Moldovanu, B. and Sela, A., (2001), "The Optimal Allocation of Prizes in Contests," American Economic Review, 91, 542-558.

Ramey, V. and Shapiro, M., (1998), “Capital Churning”, working paper, NBER.

Ramey, V. and Shapiro, M., (2001), "Displaced Capital: A Study of Aerospace Plant Closings”, Journal of Political Economy, 109, 958-92.

Report of the President's Advisory Panel on Federal Tax Reform, (2005), "Simple, Fair and Pro-Growth: Proposals to Fix America's Tax System."

Royden, H. L., (1988), “Real Analysis, Third Edition,” Prentice-Hall.

Schumpeter, J., (1934),“The Theory of Economic Development.” Harvard University Press.

Shleifer, A. and Vishny, R., (1992), "Liquidation Values and Debt Capacity: A Market Equilibrium Approach," Journal of Finance, 47, 1343-1366.

Siegel, R., (2009), “All-Pay Contests,” Econometrica, 77, 71-92.

Siegel, R., (2010), “Asymmetric Contests with Conditional Investments," American Economic Review, 100, 2230-2260.

Stein, J., (2011), "Monetary Policy as Financial-Stability Regulation," Quarterly Journal of Economics, forthcoming.

Stigler, G., (1971), “The Theory of Economic Regulation,” The Bell Journal of Economics and Management Science, 2, 3-21.

The Times-Picayune, (2011), “The Fresh Market to open in former Borders site in New Orleans," September 19. 
The Wall Street Journal, (2011), “Potential Tax Change Is Red Flag for Some Firms,” April 4.

Tirole, Jean, (2006), “The theory of corporate finance,” Princeton University Press.

U.S. News, (2011), “4 Lessons From the Demise of Borders,” July 20, 2011.

Zingales, L., (1998), "Survival of the fittest or the fattest? Exit and financing in the trucking industry," Journal of Finance, 53, 905-938.

\section{A Appendix A: Proofs}

For clarity of exposition we recap some notations. $G(t)$ is the cumulative distribution function of equilibrium exit time in the war of attrition. For firm $\theta$, given its exit strategy $t$ and debt $b$, the debt value is $D(b, t)=\frac{b}{1-\pi} G(t)$, and its equity value is

$$
E(\theta, b, t)=-(1-G(t)) k t+\int_{0}^{t}[-k x+\theta-b] d G(x)=-k \int_{0}^{t}(1-G(x)) d x+(\theta-b) G(t) .
$$

Recall the optimal exit time $T(\theta, b) \in \arg \max _{t \in[0, \infty)} E(\theta, b, t)$ where $E(\theta, b, t)$ is given in (21). The total payoff of the equity holder who chooses $b$ is:

$$
V(\theta, b) \equiv v(\theta, b, T(\theta, b))=\left(\theta+\frac{\pi b}{1-\pi}\right) G(T(\theta, b))-k \int_{0}^{T(\theta, b)}(1-G(x)) d x
$$

Focus on the equilibrium exit time range $[0, \bar{T}]$ where the upper bound $\bar{T}$ may take the value of $\infty$ (in equilibrium it might). We have the preliminary lemma to ensure that $G(t)$ is well behaved in equilibrium.

Lemma $5 G(t)$ is continuous and strictly increasing for $t \in[0, \bar{T})$.

Proof. We first show that $G(t)<G\left(t^{\prime}\right)$ for $0 \leq t<t^{\prime} \leq T$. Suppose not; then no types exit between $t$ and $t^{\prime}$. But types who exit at $t^{\prime}$ have a strictly profitable deviation to $t+\frac{t^{\prime}-t}{2}$, which saves fighting costs of $k \frac{t^{\prime}-t}{2}$ but does not affect the benefit of winning; a contradiction. This argument implies that in equilibrium, at any point in time some types are exiting in expectation.

Now suppose that $G(t)$ involves upward jumps, and w.l.o.g. say that $G\left(t^{+}\right)>G(t)$ (recall that we take the convention that $G$ is always left continuous; see footnote 15). Then types exiting at $t$ profit from waiting a bit longer: for an arbitrarily small increase in exit time $\epsilon$, they obtain a discrete increase in the winning probability but an arbitrarily small increase in the fighting cost:

$$
\begin{aligned}
& E(\theta, b, t+\epsilon)-E(\theta, b, t) \\
= & -k \int_{0}^{t+\epsilon}(1-G(x)) d x+(\theta-b) G(t+\epsilon)+k \int_{0}^{t}(1-G(x)) d x+(\theta-b) G(t) \\
= & (\theta-b)(G(t+\epsilon)-G(t))-k \int_{t}^{t+\epsilon}(1-G(t)) d x>0 .
\end{aligned}
$$

Hence types exiting at $t$ will deviate to wait longer, a contradition. Q.E.D. . 


\section{A.1 Proof of Lemma 1}

First, $\theta$ and $b$ enter $E(\theta, b, t)$ in (21) only through the effective strength $\theta-b$. Therefore if $\arg \max _{t \in[0, \infty)} E(\theta, b, t)$ is a singleton then our claim that $T$ is a function of $\theta-b$ follows. If $\arg \max _{t \in[0, \infty)} E(\theta, b, t)$ is a non-singleton set, then equity holders find it optimal to choose the largest exit time, because $D(b, t)=\frac{b}{1-\pi} G(t)$ is strictly increasing in $t$ as implied by 5 . As in the main text we now denote the optimal exit time by $T(\theta-b)$.

To prove monotonicity, consider $\theta_{1}-b_{1}$ and $\theta_{2}-b_{2}$ with $\Delta \equiv \theta_{1}-b_{1}-\left(\theta_{2}-b_{2}\right)>0$, and denote their optimal exit times by $T_{1}=T\left(\theta_{1}-b_{1}\right)$ and $T_{2}=T\left(\theta_{2}-b_{2}\right)$. We show that $T_{1} \geq T_{2}$, and $T_{1}>T_{2}$ if $G\left(T_{i}\right) \in(0,1)$, i.e., $T_{i} \in(0, \bar{T})$.

We first show weak monotonicity, $T_{1} \geq T_{2}$. Suppose not, then $T_{1}<T_{2}$. Optimally implies that $E\left(\theta_{1}, b_{1}, T_{1}\right) \geq E\left(\theta_{1}, b_{1}, T_{2}\right)$ and $E\left(\theta_{2}, b_{2}, T_{2}\right) \geq E\left(\theta_{2}, b_{2}, T_{1}\right)$. Summing these two equations yields

$$
E\left(\theta_{1}, b_{1}, T_{1}\right)-E\left(\theta_{2}, b_{2}, T_{1}\right) \geq E\left(\theta_{2}, b_{2}, T_{2}\right)-E\left(\theta_{1}, b_{1}, T_{2}\right) .
$$

Using (21), the above inequality implies that $\Delta G\left(t_{1}\right) \geq \Delta G\left(t_{2}\right)$, contradicting Lemma 5 .

Now we rule out the case that $T_{1}=T_{2}=t \in(0, \bar{T})$. Recall that

$E\left(\theta_{1}, b_{1}, t\right)=-k \int_{0}^{t}(1-G(x)) d x+\left(\theta_{1}-b_{1}\right) G(t)$, and $E\left(\theta_{2}, b_{2}, t\right)=-k \int_{0}^{t}(1-G(x)) d x+\left(\theta_{2}-b_{2}\right) G(t)$.

The optimallity of $t$ for $\theta_{2}$ implies that $\left(\theta_{2}-b_{2}\right)[G(t+\epsilon)-G(t)] \leq k \int_{t}^{t+\epsilon}(1-G(x)) d x$ for any $\epsilon$. By taking positive and negative $\epsilon$ 's, it is easy to show that $G$ is differentiable with $G^{\prime}(t) \equiv$ $g(t)=\frac{k(1-G(t))}{\theta_{2}-b_{2}}>0$ for $t<\bar{T}$, and $\left(\theta_{2}-b_{2}\right) g(t) \epsilon-k(1-G(t)) \epsilon=o(\epsilon)$. Now consider firm $\theta_{1}$ with debt $b_{1}$; we have

$$
\begin{aligned}
& \left(\theta_{1}-b_{1}\right)[G(t+\epsilon)-G(t)]-k \int_{t}^{t+\epsilon}(1-G(x)) d x \\
= & \left(\theta_{1}-b_{1}\right) g(t) \epsilon-k(1-G(t)) \epsilon+o(\epsilon) \\
> & \Delta g(t) \epsilon+\left(\theta_{2}-b_{2}\right) g(t) \epsilon-k(1-G(t)) \epsilon+o(\epsilon) \\
= & \Delta g(t) \epsilon+o(\epsilon)>0 \text { for some sufficiently small } \epsilon>0
\end{aligned}
$$

which implies that $\theta_{1}$ with debt $b_{1}$ strictly prefers to wait longer than $t$. Q.E.D.

\section{A.2 Proof of Lemma 2}

We prove the lemma in two steps.

Step 1. First, we show that in equilibrium $\theta-B(\theta)$ is increasing in $\theta$.

Suppose not. Then there exist $\theta_{1}<\theta_{2}$, whose corresponding debt choices $B\left(\theta_{1}\right)$ and $B\left(\theta_{2}\right)$ are such that

$$
\theta_{1}-B\left(\theta_{1}\right)>\theta_{2}-B\left(\theta_{2}\right) .
$$

Denote $T_{1} \equiv T\left(\theta_{1}-B\left(\theta_{1}\right)\right)$ and $T_{2} \equiv T\left(\theta_{2}-B\left(\theta_{2}\right)\right)$. Lemma 1 implies that $T_{1} \geq T_{2}$. If both firms choose corner values $\bar{T}$ or 0 in equilibrium then $T_{1}=T_{2}$. First consider the case of $\bar{T}$ so both types win the war of attrition for sure; then $\theta_{1}$ can choose a higher debt $\theta_{1}-\theta_{2}+B\left(\theta_{2}\right)>B\left(\theta_{1}\right)$ to obtain a larger debt tax subsidy but still win the war of attrition for sure. Second, if both types withdraw immediately and therefore obtain zero, $\theta_{2}$ can borrow nothing and get a strictly positive payoff. Lemma 1 then implies that $T_{1}>T_{2}$. 
The optimallity of the debt choice implies that $V(\theta, B(\theta)) \geq V(\theta, x)$ for $x \neq B(\theta)$ with $V$ given in (22). In particular, consider the deviations such that $\theta_{1}\left(\theta_{2}\right)$ chooses debt to have the effective strength of $\theta_{2}\left(\theta_{1}\right)$ in equilibrium; i.e., $\theta_{2}$ deviates to choose $b_{2}^{\prime}=\theta_{2}-\theta_{1}+B\left(\theta_{1}\right)$ and $\theta_{1}$ chooses $b_{1}^{\prime}=\theta_{1}-\theta_{2}+B\left(\theta_{2}\right)$, respectively. Because $\theta_{2}>\theta_{1}, b_{2}^{\prime}>B\left(\theta_{1}\right)>0$; and due to (23), $b_{1}^{\prime}>B\left(\theta_{1}\right)>0$. Therefore both deviations are feasible. Applying the optimallity of equilibrium debt choices to these deviations, we have $V\left(\theta_{1}, B\left(\theta_{1}\right)\right) \geq V\left(\theta_{1}, \theta_{1}-\theta_{2}+B\left(\theta_{2}\right)\right)$, and $V\left(\theta_{2}, B\left(\theta_{2}\right)\right) \geq V\left(\theta_{2}, \theta_{2}-\theta_{1}+B\left(\theta_{1}\right)\right)$. Combining both inequalities gives

$$
V\left(\theta_{1}, B\left(\theta_{1}\right)\right)-V\left(\theta_{2}, \theta_{2}-\theta_{1}+B\left(\theta_{1}\right)\right)-\left(V\left(\theta_{1}, \theta_{1}-\theta_{2}+B\left(\theta_{2}\right)\right)-V\left(\theta_{2}, B\left(\theta_{2}\right)\right)\right) \geq 0 .
$$

We now show that this inequality cannot hold. Lemma 1 shows that the exit time $T$ depends on the effective strength $\theta-b$ only:

$$
\begin{aligned}
& T_{1}=T\left(\theta_{1}, B\left(\theta_{1}\right)\right)=T\left(\theta_{2}, \theta_{2}-\theta_{1}+B\left(\theta_{1}\right)\right)=T\left(\theta_{1}-B\left(\theta_{1}\right)\right), \text { and } \\
& T_{2}=T\left(\theta_{2}, B\left(\theta_{2}\right)\right)=T\left(\theta_{1}, \theta_{1}-\theta_{2}+B\left(\theta_{2}\right)\right)=T\left(\theta_{2}-B\left(\theta_{2}\right)\right) .
\end{aligned}
$$

Then (22) implies that

$$
\begin{aligned}
& V\left(\theta_{1}, B\left(\theta_{1}\right)\right)-V\left(\theta_{2}, \theta_{2}-\theta_{1}+B\left(\theta_{1}\right)\right)=-\frac{\theta_{2}-\theta_{1}}{1-\pi} G\left(T_{1}\right), \text { and } \\
& V\left(\theta_{1}, \theta_{1}-\theta_{2}+B\left(\theta_{2}\right)\right)-V\left(\theta_{2}, B\left(\theta_{2}\right)\right)=-\frac{\theta_{2}-\theta_{1}}{1-\pi} G\left(T_{2}\right) .
\end{aligned}
$$

From Lemma 1 we know that $T_{1}>T_{2}$, and hence $G\left(T_{1}\right)>G\left(T_{2}\right)$ (Lemma 5). As a result, the term in (24) is $\frac{\theta_{2}-\theta_{1}}{1-\pi}\left(G\left(T_{2}\right)-G\left(T_{1}\right)\right)<0$, a contradiction.

Step 2. We show that in equilibrium $\theta-B(\theta)$ is strictly increasing in $\theta$.

Suppose not; then there exists an interval $\left[\theta_{1}, \theta_{2}\right]$ with $\theta_{2}>\theta_{1}$ such that $T(\theta-B(\theta))=t$ for all $\theta \in\left[\theta_{1}, \theta_{2}\right]$. Then any type $\theta$ in this interval can reduce debt by $\epsilon$ and exit a bit later than $t$ (exit time is strictly monotone in $b$ from Lemma 1 ). This leads to a strictly profitable deviation: the firm obtains at least a discrete gain in the winning probability by winning over types in the interval $\left[\theta_{1}, \theta_{2}\right]$, while only sacrificing debt tax subsidies in the order of $\epsilon$.

\section{A.3 Proof of Proposition 1}

Using Lemma 2 we can follow Bulow and Klemperer (1999) to derive equilibrium exit times in the war of attrition. The argument is almost identical to Bulow and Klemperer (1999) by simply replacing the productivity $\theta$ by $\theta-B(\theta)$, such that

$$
\hat{T}^{\prime}(\theta ; B(\cdot))=h(\theta) \frac{\theta-B(\theta)}{k} \text { for all } \theta .
$$

The only technical difference is that $\theta-B(\theta)$ might contain upward jumps. At these points, the derivative of exit time with respect to $\theta$ is not continuous. More specifically, without loss of generality, say that $B\left(\theta^{-}\right)>B(\theta)$. Then at $\theta$, we have

$$
\begin{aligned}
& \lim _{\epsilon \rightarrow 0^{+}} \frac{(\hat{T}(\theta+\epsilon ; B(\cdot))-\hat{T}(\theta ; B(\cdot)))}{\epsilon}=\hat{T}_{+}^{\prime}(\theta ; B(\cdot))=h(\theta) \frac{\theta-B(\theta)}{k}, \\
& \lim _{\epsilon \rightarrow 0^{-}} \frac{(\hat{T}(\theta+\epsilon ; B(\cdot))-\hat{T}(\theta ; B(\cdot)))}{\epsilon}=\hat{T}_{-}^{\prime}(\theta ; B(\cdot))=h(\theta) \frac{\theta-B\left(\theta^{-}\right)}{k} .
\end{aligned}
$$


However, the set of points with jumps in $\theta-B(\theta)$ must be of zero Lebesgue measure, because $\theta-B(\theta)$ is a monotone function. Therefore, if we show that $\hat{T}(\theta ; B(\cdot))$ is Lipschitz continuous, then $\hat{T}(\theta ; B(\cdot))$ is absolute continuous and therefore (7) holds (Royden, 1988). To show Lipschitz continuity, choose any $\theta \in[\underline{\theta}, \bar{\theta})$. We know that the (right and left) derivatives $h(x) \frac{x-B(x)}{k}$ are bounded for all $x \in[\underline{\theta}, \theta]$ (recall the regularity condition of hazard rate $h(\cdot)$, and boundedness of $B(x) \in[\underline{\theta}, \theta]$ ) including at the points with jumps in $B(\cdot)$. Therefore, given $\theta$ we choose a sufficient large number $M(\theta)$ such that $T(x ; B(\cdot))-T(y ; B(\cdot)) \leq M \cdot(x-y)$ for any $x, y \in[\underline{\theta}, \theta]$. As a result, $T(\theta ; B(\cdot))$ is Lipschitz continuous on $[\underline{\theta}, \theta]$, and our result follows.

\section{A.4 Proof of Theorem 1}

The proof of Theorem 1 comprises several steps. We first establish continuity and differentiability of the equilibrium debt schedule $B(\cdot)$.

Lemma 6 The debt schedule $B(\theta)$ is continuous on $(\underline{\theta}, \bar{\theta}]$. As a result, without loss of generality we assume $B(\theta)$ to be continuous on $[\underline{\theta}, \bar{\theta}]$.

Proof. Suppose that $B(\cdot)$ involves downward jumps at $\theta$ (weak monotonicity of $\theta-B(\theta)$ in Lemma 2 rules out upward jump immediately). There are two sub-cases.

First suppose that $B\left(\theta^{-}\right)>B(\theta)$, i.e., $B(\theta)$ is right continuous only. Then $\theta$ can borrow $\left[B\left(\theta^{-}\right)-B(\theta)\right] / 2$ more, while still maintaining its ranking in the war of attrition game. Due to Proposition 1, his optimal exit time $t$ is unchanged. Then from (6), this deviation gives a discrete gain in debt tax subsidies without any other losses.

Now consider the situation where $B(\theta)>B\left(\theta^{+}\right)$, i.e., $B(\theta)$ is left continuous. Then type $\theta+\epsilon$ can deviate to borrow $B(\theta)$ and vice versa. Optimallity implies that

$$
\begin{aligned}
& V(\theta+\epsilon, B(\theta))-V\left(\theta+\epsilon, B\left(\theta^{+}\right)\right)>V(\theta, B(\theta))-V\left(\theta+\epsilon, B\left(\theta^{+}\right)\right) \\
= & V(\theta, B(\theta))-V\left(\theta, B\left(\theta^{+}\right)\right)-\left[V\left(\theta+\epsilon, B\left(\theta^{+}\right)\right)-V\left(\theta, B\left(\theta^{+}\right)\right)\right]
\end{aligned}
$$

The first term is positive and at the order of $O(1)$ according to the argument in the first case ( $\theta$ only loses the debt subsidy because the deviation does not affect its exit time). The second term is at the order of $\epsilon$ because exit time is continuous. As a result, $V(\theta+\epsilon, B(\theta))>V\left(\theta+\epsilon, B\left(\theta^{+}\right)\right)$which implies that the deviation is strictly profitable.

The above argument does not apply to $B(\underline{\theta})$. It is because the firm $\underline{\theta}$ in equilibrium exits immediately and the exact debt amount raised by $\underline{\theta}$ is undetermined. Instead, we will use the continuity at $\underline{\theta}$ to determine $B(\underline{\theta})$ in the next lemma. $Q E D$. .

Lemma 7 The debt schedule $B(\theta)$ is differentiable for $(\underline{\theta}, \bar{\theta}]$ and satisfies

$$
B^{\prime}(\theta)=1-\frac{f(\theta)}{\pi F(\theta)} B(\theta) .
$$

Proof. Consider type $\theta$; by revealed preference the equilibrium payoff is higher than taking $B(\theta)+\epsilon$, i.e., (recall the definition of $v(\cdot, \cdot, \cdot)$ in (22))

$$
\begin{aligned}
0 \geq & v(\theta, B(\theta)+\epsilon, T(\theta-B(\theta)-\epsilon))-v(\theta, B(\theta), T(\theta-B(\theta))) \\
= & -\int_{\underline{\theta}}^{T^{-1}(T(\theta-B(\theta)-\epsilon))} f(y)(y-B(y)) d y+\theta F\left(T^{-1}(T(\theta-B(\theta)-\epsilon))\right)+\frac{\pi(B(\theta)+\epsilon)}{1-\pi} F\left(T^{-1}(T(\theta-B(\theta)-\epsilon))\right) \\
& +\int_{\underline{\theta}}^{T^{-1}(T(\theta-B(\theta)))} f(y)(y-B(y)) d y-\theta F\left(T^{-1}(T(\theta-B(\theta)))\right)-\frac{\pi B(\theta)}{1-\pi} F\left(T^{-1}(T(\theta-B(\theta)))\right)
\end{aligned}
$$


Let $\hat{\theta}$ be the type such that

$$
\hat{\theta}-B(\hat{\theta})=\theta-B(\theta)-\epsilon \Leftrightarrow \hat{\theta}-\theta=B(\hat{\theta})-B(\theta)-\epsilon .
$$

Because $\theta-B(\theta)$ is strictly increasing and continuous, such $\hat{\theta}<\theta$ must exist, and $\theta-\hat{\theta}>0$ converges to zero when $\epsilon$ converges to zero. Then we have

$$
\begin{aligned}
0 & \geq-\int_{\underline{\theta}}^{\hat{\theta}} f(y)(y-B(y)) d y+\theta F(\hat{\theta})+\frac{\pi(B(\theta)+\epsilon)}{1-\pi} F(\hat{\theta})+\int_{\underline{\theta}}^{\theta} f(y)(y-B(y)) d y-\theta F(\theta)-\frac{\pi B(\theta)}{1-\pi} F(\theta) \\
& =\int_{\hat{\theta}}^{\theta} f(y)(y-B(y)) d y+\theta f(\theta)(\hat{\theta}-\theta)+\frac{\pi(B(\theta)+\epsilon)}{1-\pi} F(\hat{\theta})-\frac{\pi B(\theta)}{1-\pi} F(\theta)+o(\theta-\hat{\theta}) \\
& =f(\theta)(\theta-B(\theta))(\theta-\hat{\theta})+\theta f(\theta)(\hat{\theta}-\theta)+\frac{\pi B(\theta)}{1-\pi}(F(\hat{\theta})-F(\theta))+\frac{\pi \epsilon}{1-\pi} F(\theta)+o(\theta-\hat{\theta}) \\
& =-\frac{B(\theta)}{1-\pi} f(\theta)(\theta-\hat{\theta})+\frac{\pi \epsilon}{1-\pi} F(\theta)+o(\theta-\hat{\theta}) .
\end{aligned}
$$

Note that from (26) we have

$$
\hat{\theta}-\theta=B(\hat{\theta})-B(\theta)-\epsilon \Rightarrow \epsilon=B(\hat{\theta})-B(\theta)-\hat{\theta}+\theta
$$

which implies that

$$
\begin{aligned}
0 & \geq-\frac{B(\theta)}{1-\pi} f(\theta)(\theta-\hat{\theta})+\frac{\pi(B(\hat{\theta})-B(\theta)-\hat{\theta}+\theta)}{1-\pi} F(\theta)+o(\theta-\hat{\theta}) \\
& =\left[\frac{\pi}{1-\pi} F(\theta)-\frac{B(\theta)}{1-\pi} f(\theta)\right](\theta-\hat{\theta})+\frac{\pi(B(\hat{\theta})-B(\theta))}{1-\pi} F(\theta)+o(\theta-\hat{\theta}),
\end{aligned}
$$

Therefore, we have

$$
B(\theta)-B(\hat{\theta}) \geq \frac{\pi F(\theta)-B(\theta) f(\theta)}{\pi F(\theta)}(\theta-\hat{\theta})+o(\theta-\hat{\theta}) \text { for } \theta-\hat{\theta}>0
$$

Applying the similar (but opposite) argument to deviation of $B(\theta)-\epsilon$ implies that

$$
B(\theta)-B(\hat{\theta}) \leq \frac{\pi F(\theta)-B(\theta) f(\theta)}{\pi F(\theta)}(\theta-\hat{\theta})+o(\theta-\hat{\theta}) \text { for } \theta-\hat{\theta}<0
$$

Combining both (28) and (29), we know that $B(\theta)$ is differentiable and satisfies (25). QED. .

The general closed-form solution for the ODE (25) is (with $C$ being an arbitrary constant)

$$
\begin{aligned}
& \exp \left(-\int_{\underline{\theta}}^{\theta} \frac{f(x)}{\pi F(x)} d x\right)\left(\int_{\underline{\theta}}^{\theta} \exp \left(\int_{\underline{\theta}}^{y} \frac{f(x)}{\pi F(x)} d x\right) d y+C\right) \\
= & \left(\frac{F(\underline{\theta})}{F(\theta)}\right)^{\frac{1}{\pi}}\left(\int_{\underline{\theta}}^{\theta}\left(\frac{F(y)}{F(\underline{\theta})}\right)^{\frac{1}{\pi}} d y+C\right)=(F(\theta))^{-\frac{1}{\pi}}\left(\int_{\underline{\theta}}^{\theta}(F(y))^{\frac{1}{\pi}} d y+C\right)
\end{aligned}
$$

where the last equality uses integration by parts. Since $F(\underline{\theta})=0$, any solution with $C \neq 0$ explodes at $\underline{\theta}$. Therefore $C=0$ and

$$
B(\theta)=F(\theta)^{-\frac{1}{\pi}} \int_{\underline{\theta}}^{\theta} F(y)^{\frac{1}{\pi}} d y,
$$


which is unique by construction. It is easy so show that $B(\underline{\theta})=\lim _{\theta \downarrow \underline{\theta}} B(\theta)=0$. Note that as shown in Lemma $6, B(\underline{\theta})$ itself is not determined, because $\underline{\theta}$ exits immediately so $B(\underline{\theta})$ does not matter. However, we know that types in the neighborhood of $\underline{\theta}$ must borrow almost nothing, otherwise, $\underline{\theta}$ can borrow nothing and beat these types.

Finally, we show the sufficiency of the FOC and confirm that $B(\theta)$ indeed constitutes an equilibrium. Consider type $\theta$ with debt $B(\theta)$ in equilibrium. Consider a deviation to debt level $b$. Without loss of generality we can focus on deviations such that $\theta-b \in[\underline{\theta}-B(\underline{\theta}), \bar{\theta}-B(\bar{\theta})]$. First, if $\theta-b<\underline{\theta}-B(\underline{\theta})$ ), then $\theta$ is effectively weaker than the lowest productivity type. This is unprofitable because $\theta$ exits immediately and realizes a zero payoff. Second, if $\theta-b>\bar{\theta}-B(\bar{\theta})$, then either $b$ is infeasible if $\theta-\bar{\theta}+B(\bar{\theta})<0$. Second, if $\theta-\bar{\theta}+B(\bar{\theta})>0$, then taking debt $b$ below $\theta-\bar{\theta}+B(\bar{\theta})$ provides no gain in winning the war but reduces the debt subsidy.

Now consider a deviation to debt level $b>B(\theta)$. We want to show that the marginal incentive to reduce debt at the deviation is positive, i.e., $V_{b}(\theta, b)<0$. From continuity of $\theta-B(\theta)$ we can find $\theta^{\prime}$ with $B\left(\theta^{\prime}\right)$ who has the same effective strength

$$
\theta^{\prime}-B\left(\theta^{\prime}\right)=\theta-b
$$

Because $\theta-B(\theta)$ is increasing in equilibrium (Proposition 2), $\theta^{\prime}<\theta$ which also implies that $b>B\left(\theta^{\prime}\right)$. Also, their exit time is the same as well $T(\theta-b)=T\left(\theta^{\prime}-B\left(\theta^{\prime}\right)\right)$. We compare $V_{b}(\theta, b)$ and $V_{b}\left(\theta^{\prime}, B\left(\theta^{\prime}\right)\right)$. Since $\theta^{\prime}$ chooses $b^{\prime}$ in equilibrium, $V_{b}\left(\theta^{\prime}, B\left(\theta^{\prime}\right)\right)=0$. We have

$$
\begin{aligned}
V_{b}(\theta, b) & =\frac{d E(\theta-b, T(\theta-b))}{d b}+\frac{G(T(\theta-b))}{1-\pi}-\frac{b}{1-\pi} g(T(\theta-b)) T^{\prime}(\theta-b), \\
V_{b}\left(\theta^{\prime}, B\left(\theta^{\prime}\right)\right) & =\frac{d E\left(\theta^{\prime}-B\left(\theta^{\prime}\right), T\left(\theta^{\prime}-B\left(\theta^{\prime}\right)\right)\right)}{d b}+\frac{G\left(T\left(\theta^{\prime}-B\left(\theta^{\prime}\right)\right)\right)}{1-\pi}-\frac{B\left(\theta^{\prime}\right)}{1-\pi} g\left(T\left(\theta^{\prime}-B\left(\theta^{\prime}\right)\right)\right) T^{\prime}\left(\theta^{\prime}-B\left(\theta^{\prime}\right)\right) .
\end{aligned}
$$

Because $T(\theta-b)=T\left(\theta^{\prime}-B\left(\theta^{\prime}\right)\right)$ the first two terms of $V_{b}(\theta, b)$ and $V_{b}\left(\theta^{\prime}, B\left(\theta^{\prime}\right)\right)$ are identical. We know that $T^{\prime}(\theta-b)=T^{\prime}\left(\theta^{\prime}-B\left(\theta^{\prime}\right)\right)>0$, and $g(T(\theta-b))=g\left(T\left(\theta^{\prime}-B\left(\theta^{\prime}\right)\right)\right)=$ $\frac{f\left(T^{-1}\left(T\left(\theta^{\prime}-B\left(\theta^{\prime}\right)\right)\right)\right)}{T^{\prime}\left(T^{-1}\left(T\left(\theta^{\prime}-B\left(\theta^{\prime}\right)\right)\right)\right)}=\frac{f\left(\theta^{\prime}\right) k}{h\left(\theta^{\prime}\right)\left(\theta^{\prime}-b^{\prime}\right)}>0$. Because $b>B\left(\theta^{\prime}\right)$ the third term for $\theta^{\prime}$ dominates the one for $\theta$. Thus, $V_{b}(\theta, b)<V_{b}\left(\theta^{\prime}, b^{\prime}\right)=0$. The proof for the negative deviation in debt is analogous.

\section{A.5 Proof of Proposition 2}

Setting $\pi=0$ in (27), we have $0 \geq-B(\theta) f(\theta)(\theta-\hat{\theta})+o(\theta-\hat{\theta})$ for both $\hat{\theta}>\theta$ and $\hat{\theta}<\theta$. This immediately implies that $B(\theta)=0$. QED.

\section{A.6 Proof of Corollary 1}

Direct calculation yields that

$$
\frac{\partial B(\theta ; \pi)}{\partial \pi}=\int_{\underline{\theta}}^{\theta} \frac{\partial}{\partial \pi}\left[\left(\frac{F(y)}{F(\theta)}\right)^{\frac{1}{\pi}}\right] d y=\frac{1}{\pi^{2}} \int_{\underline{\theta}}^{\theta}\left(\frac{F(y)}{F(\theta)}\right)^{\frac{1}{\pi}} \ln \left(\frac{F(\theta)}{F(y)}\right) d y>0,
$$

and $\frac{\partial T(\theta ; B(\cdot ; \pi))}{\partial \pi}=\int_{\underline{\theta}}^{\theta} \frac{h(x)}{k}\left[-\frac{\partial B(x ; \pi)}{\partial \pi}\right] d x<0$. QED.

\section{A.7 Proof of Proposition 3}

Direct calculation yields $\frac{d S(\pi)}{d \pi}=\mathbb{E}_{\theta}\left[\int_{\underline{\theta}}^{\theta} f(y) \frac{\partial B(y ; \pi)}{\partial \pi} d y\right]>0$. QED. 


\section{B Appendix B: Duration of Distress}

\section{B.1 Proof of Proposition 4}

We have given the main argument of how we derive the equilibrium debt schedule and equilibrium exit times in the main text. The only thing is left to show is the existence and uniqueness of threshold $\hat{\theta}$. Because the right hand side of the equation $k T_{d}=k \widehat{T}(\hat{\theta})+\hat{\theta}-B(\hat{\theta})$ is strictly increasing in $\hat{\theta}$, uniqueness follows. Because the right hand side is increasing from $\bar{\theta}$ to $k \widehat{T}(\bar{\theta})+\bar{\theta}-B(\bar{\theta}) \hat{\theta}$ exists if

$$
k T_{d} \in(\bar{\theta}, k \widehat{T}(\bar{\theta})+\bar{\theta}-B(\bar{\theta})) .
$$

Otherwise, $\hat{\theta}=\bar{\theta}$, and the solution is the same as in the benchmark model. Finally, the comparative statics with respect to $\pi$ and $T_{d}$ are straightforward.

\section{B.2 Characterization of threshold}

Here we solve analytically for the threshold type $\hat{\theta}$ for the distribution $F(\theta)=\lambda \theta^{\alpha}$. Then $B(\theta ; \pi)=$ $\frac{\pi}{\alpha+\pi} \theta$ for $\theta<\hat{\theta}$. Denote the equilibrium exit time without a debt subsidy by

$$
T_{0}(\theta)=\int_{0}^{\theta} \frac{\lambda \alpha y^{\alpha}}{1-\lambda y^{\alpha}} d y
$$

For $\pi>0, \hat{\theta}(\pi)-B(\hat{\theta}(\pi))=\frac{\alpha}{\alpha+\pi} \hat{\theta}(\pi)$, and

$$
\widehat{T}(\hat{\theta}(\pi) ; B(\theta ; \pi))=\frac{\alpha}{\alpha+\pi} T_{0}(\hat{\theta}(\pi))=\frac{\alpha}{\alpha+\pi} \int_{0}^{\hat{\theta}(\pi)} \frac{\lambda \alpha y^{\alpha}}{1-\lambda y^{\alpha}} d y .
$$

$\hat{\theta}(\pi)$ solves the following equation by rearranging (18):

$$
k T_{0}(\hat{\theta}(\pi))+\hat{\theta}(\pi)=\frac{\alpha+\pi}{\alpha} k T_{d} .
$$

One can calculate the increasing function on the left hand side $k T(y)+y$ as ${ }_{2} \mathbb{F}_{1}$ is the hypergeometric function)

$$
k T(y)+y=\int_{0}^{y} \frac{\lambda \alpha x^{\alpha}}{1-\lambda x^{\alpha}} d x+y=\alpha y_{2} \mathbb{F}_{1}\left(1, \frac{1}{\alpha}, 1+\frac{1}{\alpha}, \lambda y^{\alpha}\right)+(1-\alpha) y .
$$

Thus given $\pi$ we can easily solve for $\hat{\theta}(\pi)$ numerically. Also, the total welfare is

$$
\begin{aligned}
S(\pi) & =\mathbb{E}_{\theta}\left[(s(\theta))_{\theta \leq \hat{\theta}(\pi)}+\left(-k T_{d}+\theta\right)_{\theta>\hat{\theta}(\pi)}\right] \\
& =\lambda^{2} \alpha \frac{\alpha+\pi+\pi \alpha}{(\alpha+\pi)(1+\alpha)} \frac{1}{2 \alpha+1}(\hat{\theta}(\pi))^{2 \alpha+1}-\left(1-\lambda(\hat{\theta}(\pi))^{\alpha}\right) k T_{d}+\frac{\lambda \alpha}{1+\alpha}\left[(\bar{\theta})^{\alpha+1}-(\hat{\theta}(\pi))^{\alpha+1}\right]
\end{aligned}
$$




\section{Appendix C: Asymmetric Information in Financing}

\section{C.1 Proof of Lemma 3}

We use the generalized envelope theorem in Milgrom and Segal (2002). For $E(\theta, b, t)$, treat $\theta$ as the parameter and $t$ is the choice variable, while $b$ is just some index. Then

$$
\mathcal{E}(\theta, b) \equiv \sup _{t \in[0, \infty)} E(\theta, b, t)
$$

Suppose $\theta<\theta^{\prime}$ and $B(\theta)<B\left(\theta^{\prime}\right)$. Then from revealed preference in equilibrium, we have

$$
\begin{aligned}
D(B(\theta))+\mathcal{E}(\theta, B(\theta)) & \geq D\left(B\left(\theta^{\prime}\right)\right)+\mathcal{E}\left(\theta, B\left(\theta^{\prime}\right)\right), \\
D\left(B\left(\theta^{\prime}\right)\right)+\mathcal{E}\left(\theta^{\prime}, B\left(\theta^{\prime}\right)\right) & \geq D(B(\theta))+\mathcal{E}\left(\theta^{\prime}, B(\theta)\right) .
\end{aligned}
$$

Summing both equations yields

$$
\mathcal{E}(\theta, B(\theta))+\mathcal{E}\left(\theta^{\prime}, B\left(\theta^{\prime}\right)\right)-\mathcal{E}\left(\theta, B\left(\theta^{\prime}\right)\right)-\mathcal{E}\left(\theta^{\prime}, B(\theta)\right) \geq 0
$$

From Eq. (2), we can derive

$$
E_{\theta}(\theta, b, t)=G(t)
$$

Notice that $E_{\theta}(\theta, b, t)$ is independent of $\theta$ and $b$ and is bounded. Then Theorem 2 of Milgrom and Segal (2002) implies that

$$
\mathcal{E}(\theta, b)=\mathcal{E}(\underline{\theta}, b)+\int_{\underline{\theta}}^{\theta} E_{\theta}(x, b, T(y, b)) d y .
$$

Then

$$
\begin{aligned}
& \mathcal{E}(\theta, B(\theta))+\mathcal{E}\left(\theta^{\prime}, B\left(\theta^{\prime}\right)\right)-\mathcal{E}\left(\theta^{\prime}, B(\theta)\right)-\mathcal{E}\left(\theta, B\left(\theta^{\prime}\right)\right) \\
= & \mathcal{E}(\underline{\theta}, B(\theta))+\int_{\underline{\theta}}^{\theta} E_{\theta}(y, B(\theta), T(y, B(\theta))) d y+\mathcal{E}\left(\underline{\theta}, B\left(\theta^{\prime}\right)\right)+\int_{\underline{\theta}}^{\theta^{\prime}} E_{\theta}\left(y, B\left(\theta^{\prime}\right), T\left(y, B\left(\theta^{\prime}\right)\right)\right) d y \\
& -\mathcal{E}(\underline{\theta}, B(\theta))-\int_{\underline{\theta}}^{\theta^{\prime}} E_{\theta}(y, B(\theta), T(y, B(\theta))) d y-\mathcal{E}\left(\underline{\theta}, B\left(\theta^{\prime}\right)\right)-\int_{\underline{\theta}}^{\theta} E_{\theta}\left(y, B\left(\theta^{\prime}\right), T\left(y, B\left(\theta^{\prime}\right)\right)\right) d x \\
= & \int_{\theta}^{\theta^{\prime}}\left[E_{\theta}\left(y, B\left(\theta^{\prime}\right), T\left(y, B\left(\theta^{\prime}\right)\right)\right)-E_{\theta}(y, B(\theta), T(y, B(\theta)))\right] d y \\
= & \int_{\theta}^{\theta^{\prime}}\left[G\left(T\left(y, B\left(\theta^{\prime}\right)\right)\right)-G(T(y, B(\theta)))\right] d y
\end{aligned}
$$

Because $G(t)$ is strictly increasing (Lemma 5), and from 1 we know that $T\left(y, B\left(\theta^{\prime}\right)\right)<T(y, B(\theta))$ for any type $y$. Then:

$$
\mathcal{E}(\theta, B(\theta))+\mathcal{E}\left(\theta^{\prime}, B\left(\theta^{\prime}\right)\right)-\mathcal{E}\left(\theta, B\left(\theta^{\prime}\right)\right)-\mathcal{E}\left(\theta^{\prime}, B(\theta)\right)<0
$$

which contradicts with $\mathcal{E}\left(\theta, b^{\prime}\right)-\mathcal{E}(\theta, b)>\mathcal{E}\left(\theta^{\prime}, b^{\prime}\right)-\mathcal{E}\left(\theta^{\prime}, b\right)$. Therefore the equilibrium debt schedule $B(\cdot)$ is non-increasing in $\theta$. It follows that $\theta-B(\theta)$ is strictly increasing in $\theta$. 


\section{C.2 Proof of Lemma 4}

For any $\theta$, such that $\theta-B(\theta) \leq 0$ the firm makes a loss even conditional on winning the war of attrition for any positive exit time. Independent of the strategies of other firms, these firms leave instantaneously. For sufficiently productive types such that $\theta>\underline{\hat{\theta}} \equiv \inf \{\theta: \theta-B(\theta)>0\}$ Lemma 3 guarantees that the order of effective strength in the war of attrition is the same as the order of productivity. We can then apply the proof of Proposition 1.

\section{C.3 Proof of Proposition 5}

Result 1. Without the tax subsidy, $\pi=0$, the unique equilibrium is all-equity financing, i.e., $B(\theta)=$ 0 for all $\theta$.

Consider a firm $\theta$, which borrows $B(\theta)=b>0$, with optimal exit time $t^{*}=T(\theta-b)$ in the war of attrition game. Suppose that its debt is fairly priced by the bank (e.g., in a separating equilibrium), so that $D(b)=G(T(\theta, b)) b$ (setting $\pi=0$ in (4)). Therefore, by summing up (2) and (19), and using (22) the equity holder's ex ante value is

$$
E\left(\theta, b, t^{*}\right)+D(b)=E\left(\theta, b, t^{*}\right)+G\left(t^{*}\right) b=\theta G\left(t^{*}\right)-k \int_{0}^{t^{*}}(1-G(x)) d x
$$

Define

$$
V(\theta, t) \equiv \theta G(t)-k \int_{0}^{t}(1-G(x)) d x
$$

to be the firm value without a tax subsidy, given productivity $\theta$ and exit time $t$; note that the firm value is independent of $b$. Importantly, however, $T^{*}=\arg \max _{t} E(\theta, b, t ; \pi=0)$, so $T^{*}$ does not maximize the firm value $V(\theta, t)$. Now consider the deviation of setting $b=0$; then the equity holder will take another optimal exit strategy, say $T^{* *}$, such that

$$
T^{* *}=\arg \max _{t} E(\theta, 0, t ; \pi=0)=\arg \max _{t} V(\theta, t)
$$

that maximizes firm value directly and $V\left(\theta, T^{* *}\right) \geq V\left(\theta, T^{*}\right)$. From Lemma 1 we know that $T^{* *} \neq$ $T^{*}$; therefore $V\left(\theta, T^{* *}\right)>V\left(\theta, T^{*}\right)$. As a result, the equity holder prefers zero debt financing.

If the equilibrium of the financing game is pooling in a given region, then there always exists a type whose debt price is below the fair price $G\left(T^{*}\right) b \geq D(b)$. Then

$$
E\left(\theta, b, T^{*}\right)+D(b) \leq E\left(\theta, b, T^{*}\right)+G\left(T^{*}\right) b=V\left(\theta, T^{*}\right)<V\left(\theta, T^{* *}\right) .
$$

Result 2. The exit times follow straight from Lemma 4.

Result 3. The social planner chooses a strictly positive $\pi>0$.

We show that the social planner can improve welfare by setting a positive tax subsidy $\pi>0$ to support a pooling equilibrium with $B(\theta)=b$ for all $\theta \in \Theta$. In a pooling equilibrium all types propose debt level $b$ to the bank, $D(\theta)=b$, and obtain $D(b)$ from the bank. ${ }^{30}$ Welfare for a given level of debt is closely related to welfare in the baseline model from 17 . The only difference is that only types who choose less debt than their productivity $\theta>b$ generate positive welfare, and impose cost on other firms.

$$
S(b)=\int_{\max (b, \underline{\theta})}^{\bar{\theta}}\left(\theta F(\theta)-\int_{\max (b, \underline{\theta})}^{\theta}(y-b) f(y) d y\right) f(\theta) d \theta
$$

\footnotetext{
${ }^{30} \mathrm{~A}$ more complete characterization is available from the authors upon request. We show that any equilibrium debt schedule has a pooling region for the low types, and then the proof proceeds along similar lines.
} 
First note that welfare in 31 equals welfare in the baseline model 17, for $\theta>b \geq 0$. Then increasing $b$ marginally above 0 clearly leads to a welfare increase since $\frac{\partial S(b)}{\partial b}=S(b)=\int_{\theta}^{\bar{\theta}} F(\theta) f(\theta) d \theta>$ 0 . Further we can also show that welfare increases for a marginal increase of $b$ above $\underline{\theta}$ :

$$
\left.\frac{\partial S(b)}{\partial b}\right|_{b=\underline{\theta}}=-b F(b)+\left.\int_{b}^{\bar{\theta}}(F(\theta)-F(b)) f(\theta) d \theta\right|_{b=\underline{\theta}}=\int_{\underline{\theta}}^{\bar{\theta}} F(\theta) f(\theta) d \theta>0
$$

Note that a pooling equilibrium satisfies the requirement from Lemma 1 that $B(\cdot)$ is not increasing in $\theta$. We support the equilibrium with the belief that off-equilibrium deviations are from the least productive type $\underline{\theta}$. Note that the tax subsidy affects all firms the same way through the debt pricing $D(b)$, thus the most productive type $\bar{\theta}$ has the highest incentive to deviate from the pooling equilibrium. The necessary and sufficient condition for the pooling condition to exist is then for the $\bar{\theta}$ not to deviate, which is $D(b)+E(\bar{\theta}, b, T(\bar{\theta}-b)) \geq E(\bar{\theta}, 0, T(\bar{\theta}))$ or, $\int_{\max (b, \underline{\theta})}^{\bar{\theta}} F(\theta) f(\theta) d \theta \geq 1-\pi$ which holds for sufficiently high $\pi$. QED.

\section{Appendix D: Coasian Solution}

\section{D.1 Proof of Proposition 6}

For simplicity we assume $\Theta=[0, \bar{\theta}]$ where $\bar{\theta}$ is finite.

Monotonicity in bid rejection. Suppose not; then there exists $\theta_{1}<\theta_{2}$, such that $\theta_{1}$ rejects the offer and $\theta_{2}$ accepts the offer. Let $\Theta_{Y}\left(\Theta_{N}=\Theta \backslash \Theta_{Y}\right)$ be the set of all types who accept (reject) the offer, and let $\operatorname{Pr}(Y)=\operatorname{Pr}\left(\theta \in \Theta_{Y}\right)$. Denote by $V\left(\theta ; \Theta_{1}, \Theta_{2}\right)$ the payoff to firm $\theta$ after sale decisions become public, where firm $\theta$ believes that its opponent is from $\Theta_{1}$, while the opponent believes that she is playing against a firm from $\Theta_{2}$. The incentive compatibility conditions for both types require that (recall that the rejection of $\theta_{1}$ implies that $\theta_{1}$ strictly prefers rejection)

$$
\begin{aligned}
& \operatorname{Pr}(Y) V\left(\theta_{1} ; \Theta_{Y}, \Theta_{N}\right)+(1-\operatorname{Pr}(Y)) V\left(\theta_{1} ; \Theta_{N}, \Theta_{N}\right)>p \\
& p \geq \operatorname{Pr}(Y) V\left(\theta_{2} ; \Theta_{Y}, \Theta_{N}\right)+(1-\operatorname{Pr}(Y)) V\left(\theta_{2} ; \Theta_{N}, \Theta_{N}\right) .
\end{aligned}
$$

Combining and rearranging, we require that

$$
\operatorname{Pr}(Y)\left[V\left(\theta_{1} ; \Theta_{Y}, \Theta_{N}\right)-V\left(\theta_{2} ; \Theta_{Y}, \Theta_{N}\right)\right]>(1-\operatorname{Pr}(Y))\left[V\left(\theta_{2} ; \Theta_{N}, \Theta_{N}\right)-V\left(\theta_{1} ; \Theta_{N}, \Theta_{N}\right)\right] .
$$

In a war of attrition, $\theta_{2}$ can follow $\theta_{1}$ exit strategy and freely dispose $\theta_{2}-\theta_{1}>0$. Thus $V\left(\theta_{1} ; \Theta_{Y}, \Theta_{N}\right)-$ $V\left(\theta_{2} ; \Theta_{Y}, \Theta_{N}\right) \leq 0$ and $V\left(\theta_{2} ; \Theta_{N}, \Theta_{N}\right)-V\left(\theta_{1} ; \Theta_{N}, \Theta_{N}\right) \geq 0$, and (32) cannot hold, a contradiction.

Existence and uniqueness. Fix $p$ and let $\hat{\theta}$ be the solution to $\hat{\theta} F(\hat{\theta})=p$. We show that the firm $\theta_{i}=\hat{\theta}$ is indifferent between accepting and rejecting. By accepting, it always obtains $p$. Suppose firm $i$ rejects the offer. If the other firm, $\theta_{j}$, rejects, then $\theta_{j}>\hat{\theta}$ which occurs with probability $1-F(\hat{\theta})$. Firm $i$ enters the war of attrition with this stronger opponent and her expected payoff is zero. If the other firm accepts the offer, with probability $F(\hat{\theta})$, in equilibrium firm $C$ acquires the assets, but does not enter the war, and firm $i$ wins the war and obtains $\hat{\theta}$. Therefore the indifference condition implies that $\hat{\theta} F(\hat{\theta})=p$. Because $\hat{\theta} F(\hat{\theta})$ is strictly monotone in $\hat{\theta}$, the cutoff $\hat{\theta}$ is unique, and this equilibrium is unique. 
Now we verify that the proposed strategies comprise an equilibrium. Given the monotonicity of the bid rejection strategy, we know that it is optimal for types below $\hat{\theta}$ to accept the offer and types above $\hat{\theta}$ to reject it. Now we verify that the war of attrition game is indeed an equilibrium. If both firms reject the offer, the war of attrition is one with the truncated type distribution with lower bound $\hat{\theta}$. If one firm rejects and the other accepts, then it is obvious that the firm which rejected the offer and saw its opponent accepting it, will enter the war (because in equilibrium she expects firm $C$ to immediately fold). Finally, after buying a weak firm $\theta \leq \hat{\theta}$, firm $C$ will find it optimal not to enter the war of attrition. On this off-equlibrium path the opponent plays according to standard war of attrition in Proposition 2 with lower bound $\hat{\theta}$ as a common belief. In this game $\hat{\theta}$ drops out immediately, therefore firm $C$ with $\theta \leq \hat{\theta}$ finds it optimal to exit immediately as well.

Negative expected profits. Now we compute the firm $C$ 's expected profits for any $p>0$. Since the bidding price $p(\widehat{\theta})=\widehat{\theta} F(\widehat{\theta})$ is monotone in the equilibrium cutoff type $\hat{\theta}$, firm $C$ can effectively choose $\widehat{\theta}$. The total equilibrium expected profits as a function of $\widehat{\theta}$ are:

$$
\begin{aligned}
2 \Pi(\widehat{\theta}) & =\int_{0}^{\widehat{\theta}} \int_{0}^{\widehat{\theta}}\left(\max \left(\theta_{1}, \theta_{2}\right)-2 p(\widehat{\theta})\right) f\left(\theta_{1}\right) f\left(\theta_{2}\right) d \theta_{1} d \theta_{2}-2 p(\widehat{\theta}) F(\widehat{\theta})(1-F(\widehat{\theta})) \\
& =\int_{0}^{\widehat{\theta}} \int_{0}^{\widehat{\theta}}\left(\max \left(\theta_{1}, \theta_{2}\right)\right) f\left(\theta_{1}\right) f\left(\theta_{2}\right) d \theta_{1} d \theta_{2}-2 \widehat{\theta} F^{2}(\widehat{\theta}) .
\end{aligned}
$$

Here, the first term captures the situation where both firms accept the offer. Firm $C$ pays $p(\widehat{\theta})$ to each firm and internalizes externalities by closing the less profitable firm. In the situation where only one firm accepts, which occurs with probability $2 F(\widehat{\theta})(1-F(\widehat{\theta}))$, firm $C$ pays $p(\widehat{\theta})$ to one firm, and immediately exits. When both firms reject firm $C$ has zero payoffs. Since firm $C$ is effectively choosing $\widehat{\theta}$, the first order impact of $\widehat{\theta}$ on profits is

$$
\frac{\partial \Pi}{\partial \hat{\theta}}=-\widehat{\theta} F(\widehat{\theta}) f(\widehat{\theta})-F^{2}(\widehat{\theta})<0
$$

and strictly negative for $\widehat{\theta}>0$. Further, since $\Pi(\widehat{\theta}=0)=0$, the strictly negative slope implies that $\Pi(\widehat{\theta})<0$ for all positive $\widehat{\theta}$ (i.e. $p>0$ ). Q.E.D.

\section{D.2 Proof of Corollary 2}

We impose off-equilibrium beliefs, that closely correspond to the ones for unconditional offers: In equilibrium the strong firm $\theta_{i}>\hat{\theta}$ rejects the bid and the the weak firm $\theta_{j}<\hat{\theta}$ chooses to sell. Because bids are conditional, the bid fails. Suppose that $\theta_{j}$ who is now revealed to be weak-enters the second stage war of attrition instead of exiting immediately as the equilibrium strategy suggests. We assume that in the war of attrition the strong opponent forgets that the weak firm has reveled itself to be weak and treats the weak firm as the one who should have rejected the bid. The equilibrium is monotone even under this harsh off-equilibrium belief against monotone strategies.

Monotonicity in rejecting strategy. First we show that for $\theta_{2}>\theta_{1}$, if $\theta_{1}$ rejects the offer then $\theta_{2}$ rejects it as well. We use the same notation as in the proof of Proposition 6. Suppose the strategy is not monotonic, then the incentive compatibility conditions for both types require that

$$
\begin{aligned}
\operatorname{Pr}(Y) V\left(\theta_{1} ; \Theta_{Y}, \Theta_{N}\right)+(1-\operatorname{Pr}(Y)) V\left(\theta_{1} ; \Theta_{N}, \Theta_{N}\right) & >\operatorname{Pr}(Y) p+(1-\operatorname{Pr}(Y)) V\left(\theta_{1} ; \Theta_{N}, \Theta_{Y}\right) \\
\operatorname{Pr}(Y) p+(1-\operatorname{Pr}(Y)) V\left(\theta_{2} ; \Theta_{N}, \Theta_{Y}\right) & \geq \operatorname{Pr}(Y) V\left(\theta_{2} ; \Theta_{Y}, \Theta_{N}\right)+(1-\operatorname{Pr}(Y)) V\left(\theta_{2} ; \Theta_{N}, \Theta_{N}\right.
\end{aligned}
$$


Combine and rearrange, we require that

$$
\begin{aligned}
& \operatorname{Pr}(Y)\left(V\left(\theta_{1} ; \Theta_{Y}, \Theta_{N}\right)-V\left(\theta_{2} ; \Theta_{Y}, \Theta_{N}\right)\right) \\
>\quad & (1-\operatorname{Pr}(Y))\left[V\left(\theta_{1} ; \Theta_{N}, \Theta_{Y}\right)-V\left(\theta_{1} ; \Theta_{N}, \Theta_{N}\right)+V\left(\theta_{2} ; \Theta_{N}, \Theta_{N}\right)-V\left(\theta_{2} ; \Theta_{N}, \Theta_{Y}\right)\right]
\end{aligned}
$$

Under the off equilibrium beliefs specified in Proposition 6, once the war of attrition has started, firms' strategies are independent of the previous decision to sell. This implies that the payoffs to entering the war of attrition are independent of a decision to sell. As a result $V\left(. ; ., \Theta_{N}\right)=V\left(. ; ., \Theta_{Y}\right)$, therefore the second line in (33) is zero. And, since $\theta_{2}$ can freely dispose $\theta_{2}-\theta_{1}>0, V\left(\theta_{1} ; \Theta_{Y}, \Theta_{N}\right)-$ $V\left(\theta_{2} ; \Theta_{Y}, \Theta_{N}\right) \leq 0$. Therefore (33) cannot hold and we have a contradiction.

Now we describe the equilibrium: Under the off equilibrium belief specified in Proposition 6 , there exists a unique (pure strategy) symmetric equilibrium. In this equilibrium, given the offer price $p$, define the cutoff $\widehat{\theta}=p$. All firms below $\hat{\theta}=p$ accept the bid and all firms above $\hat{\theta}$ reject the bid. If the bid fails, the firm who accepted the bid (if there exists such a firm) exits immediately. If both firms reject the bid, they compete in a war of attrition with exit times in Proposition 2 with productivity distribution truncated below at $\hat{\theta}$.

We omit the proof for uniqueness of existence which is similar to that of Proposition 6 (the detailed argument is available upon request).

Negative expected profits. Now we compute firm $C$ 's expected profits for any $p>0$, and show that they are strictly negative. Because the offer is contingent, the buyer only earns profits when both firms accept the bid. Since $C$ 's profits come from internalizing externalities, it will bid such that, if successful, it closes the less productive firm. In exchange, it pays $p$ to each firm. Since $\widehat{\theta}=p$, firm $C$ can effectively choose $\widehat{\theta}$. The equilibrium profits are:

$$
\begin{aligned}
\Pi(\widehat{\theta}) & =\frac{1}{2} \int_{0}^{\widehat{\theta}} \int_{0}^{\widehat{\theta}}\left(\max \left(\theta_{1}, \theta_{2}\right)-2 p(\widehat{\theta})\right) f\left(\theta_{1}\right) f\left(\theta_{2}\right) d \theta_{1} d \theta_{2} \\
& =\int_{0}^{\widehat{\theta}} \int_{0}^{\widehat{\theta}}\left(\frac{\max \left(\theta_{1}, \theta_{2}\right)}{2}\right) f\left(\theta_{1}\right) f\left(\theta_{2}\right) d \theta_{1} d \theta_{2}-\widehat{\theta} F^{2}(\widehat{\theta}) .
\end{aligned}
$$

The marginal impact of cutoff $\hat{\theta}$ on the expected profits is

$$
\begin{aligned}
2 \frac{\partial \Pi}{\partial \hat{\theta}} & =\int_{0}^{\widehat{\theta}} \max (\widehat{\theta}, \theta) f(\widehat{\theta}) f(\theta) d \theta-F^{2}(\widehat{\theta})-2 \widehat{\theta} F(\widehat{\theta}) f(\widehat{\theta}) \\
& =F(\widehat{\theta})[\widehat{\theta} f(\widehat{\theta})-F(\widehat{\theta})-2 \widehat{\theta} f(\widehat{\theta})] \leq 0,
\end{aligned}
$$

and strictly negative for $\widehat{\theta}>0$. Further, since $\Pi(\widehat{\theta}=0)=0$, the strictly negative slope implies that $\Pi(\widehat{\theta})<0$ for all positive $\widehat{\theta}$ (i.e. $p>0$ ). Q.E.D.

\section{D.3 Proof of Proposition 7}

We first show that the firm's equilibrium time of sale is increasing in firms' type. Before either firm $i$ or $j$ sell, both firms face similar payoffs as in (2), with two key differences. First, each firm has the option to sell to firm $C$ at $t$ and receive $p_{1}(t)$. Second, whichever firm chooses not to sell will compete with firm $C$, but it can also choose to sell its asset to $C$ for $p_{2}(s, t)$ at any time $s>t$. Without loss of generality, consider firm $i$ and suppose that its opponent's selling time distribution is $G_{S}$. Because 
we are focusing on symmetric equilibria, $G_{S}$ is independent of firm's identity. Therefore, the value of firm with productivity $\theta$ and selling time $t$ is

$$
V(\theta, t)=\left(1-G_{S}(t)\right)\left(-k t+p_{1}(t)\right)+\int_{0}^{t}\left[-k x+V^{C}(\theta, x)\right] d G_{S}(x),
$$

where the first term is firm $i$ 's payoff if she is the first firm to accept $C$ 's offer. The second term is her payoff if the opponent sells first. In this term, the first part is the cost of competing with firm $j$, and the second term $V^{C}(\theta, x)$ gives the continuation value of competing with firm $C$ if the opponent sells itself to $C$ at time $x$.

Suppose that $\theta<\theta^{\prime}$ but they choose $t>t^{\prime}$ in equilibrium. Then $V\left(\theta^{\prime}, t^{\prime}\right) \geq V\left(\theta^{\prime}, t\right)$ and $V(\theta, t) \geq V\left(\theta, t^{\prime}\right)$. Moreover, because we break ties such that the firm accepts an offer whenever indifferent, ${ }^{31}$ we can show that the first inequality is strict: $V(\theta, t)>V\left(\theta, t^{\prime}\right)$. Suppose that $V(\theta, t)=V\left(\theta, t^{\prime}\right)$. Because $t>t^{\prime}$, firm $\theta$ must strictly prefer rejecting at $t^{\prime}$, i.e. there exits some later selling time $t^{*}>t^{\prime}$ such that $V\left(\theta, t^{*}\right)>V\left(\theta, t^{\prime}\right)=V(\theta, t)$. This contradicts the fact that $V(\theta, t)$ is the optimal selling strategy.

Combining the inequalities we obtain

$$
V\left(\theta^{\prime}, t^{\prime}\right)-V\left(\theta, t^{\prime}\right)>V\left(\theta^{\prime}, t\right)-V(\theta, t) .
$$

Because of free disposal $V^{C}(\theta, x) \geq V^{C}\left(\theta^{\prime}, x\right)$ for $\theta>\theta^{\prime}$. Let $\Delta V^{C}(\theta, x)=V^{C}\left(\theta^{\prime}, x\right)-$ $V^{C}(\theta, x) \geq 0$. Using (34), we have $V\left(\theta^{\prime}, t\right)-V(\theta, t)=\int_{0}^{t} \Delta V^{C}(\theta, x) d G(x)$.

$$
\frac{d\left[V\left(\theta^{\prime}, t\right)-V(\theta, t)\right]}{d t}=\Delta V^{C}(\theta, t) d G_{S}(t) \geq 0,
$$

Then $V\left(\theta^{\prime}, t^{\prime}\right)-V\left(\theta, t^{\prime}\right) \leq V\left(\theta^{\prime}, t\right)-V(\theta, t)$ because $t^{\prime}<t$. This contradicts with (35), and therefore the time to accept the offer is increasing in firm productivity.

Now we show that firm $C$ cannot earn positive profits. If firms sell to $C$ at different times, it is common knowledge that the first firm $C$ bought is strictly weaker. We focus subgame equilibria in which strictly weaker firms exit immediately. Therefore firm $C$ exits immediately and loses money in paying the firm who sold first.

Firm $C$ still might be able to earn positive profits if it can induce both firms to sell at the same time. Because of monotonicity, at any point in time, the distribution of types that has not sold yet is the original type distribution but potentially truncated from below at some $\widehat{\theta}$. Consider the last time at which both firms might sell. This corresponds to the highest cutoff $\widehat{\theta}$. Since $\widehat{\theta}$ is bounded above by $\bar{\theta}$, such a time exists. Then we can evaluate the profit of firm $C$ at this highest cutoff. Wlog, firm $C$ must offer a non-zero price-otherwise no firms will sell. This subgame corresponds to the static time- 0 game analyzed in Proposition 6, and the same argument as in Proposition 6 implies that firm $C$ will incur a strictly negative profit at $\widehat{\theta}$. This violates the requirement that firm $C$ cannot commit to offer prices that incur a negative expected profit. QED.

\footnotetext{
${ }^{31}$ The argument is similar if we break ties the other way.
} 